\title{
UNTERSUCHUNGEN ÜBER DIE ABHÄNGIGKEIT DER NACHKOMMENSRATE VON VARROA JACOBSONI OUD. VOM BEFALLSGRAD DER BIENENVÖLKER
}

\author{
Rudolf MOOSBECKHOFER, Martin FABSICZ, Astrid KOHLICH \\ Höhere Bundeslehr- und Versuchsanstalt für Wein- und Obstbau mit Institut \\ für Bienenkunde Klosterneuburg \\ Institut für Bienenkunde, Hauptstraße 14, A-2540 Bad Vöslau
}

\section{ZUSAMMENFASSUNG}

An 33 Völkern von Apis mellifera L. carnica wurde der Einfluß der Befallsstärke auf die Fortpflanzungsbilanz von Varroa jacobsoni Oud. untersucht. Prozent.

Der Anteil der varroabefallenen Bienen lag durchschnittlich bei $27 \%$, der Brutbefall betrug 50

Mit zunehmendem Puppenalter nahm der Brutbefall mit Varroamilben ab. Dies ist darauf zurückzuführen, daß in den mehrfach befallenen Zellen dic Puppen absterben und von den Bienen ausgeräumt werden.

Der Anteil befallener Zellen ohne Varroa-Fortpflanzung schwankte von Volk zu Volk sehr stark. Im Durchschnitt lag er bei 7 Prozent. Ausschließlich männliche Nachkommen waren im Durchschnitt bei $2,9 \%$ der befallenen Zellen anzutreffen.

Zwischen den Völkern zeigten sich große Unterschiede in der Nachkommenzahl pro Varroa. Das Minimum betrug 0,19, das Maximum 2,14 Nachkommen/Varroa.

Der prozentuelle Anteil von Zellen mit negativer Varroa-Vermehrungsbilanz steigt höchstsignifikant an, wenn der Parasitierungsgrad pro Zelle zunimmt.

Mit steigendem Brutbefall stieg die Anzahl der pro Zelle eingedrungenen Varroaweibchen höchstsignifikant an.

Dic Anzahl der Nachkommen pro Varroa nimmt mit steigender Anzahl der Mütter pro Zclle höchstsignifikant ab.

Bei rund $30 \%$ aller Streckmaden bzw. Vorpuppen wurden bereits Eier oder Larven der Varroamilbe gefunden.

Möglicherweise handelt es sich bei diesen $30 \%$ der Varroaweibehen, die offenbar frühzeitig Eier legen, um solche, die sofort nach dem Schlupf zum zweiten Mal eine Brutzelle zur Eiablage aufsuchen, ohne vorher längere Zeit an Bienen zu saugen.

Für die Praxis erscheint es empfehlenswert, Völker mit einem hohen Infertilitätsgrad oder späten Beginn der Eiablage der Varroaweibchen bevorzugt für die Nachzucht zu verwenden. 


\section{EINLEITUNG}

Die auf der Honigbiene parasitierende Varroamilbe dezimiert seit ihrem Vordringen nach Österreich vermutlich im Jahre 1980 in immer stärkerem Ausmaß die einheimischen Bienenstände. Ohne rechtzeitige Maßnahmen zur Reduktion des Varroabefalles ist in vielen Gebieten Österreichs die Bienenzucht nicht mehr aufrechtzuerhalten.

Beobachtungen des Instituts für Bienenkunde in den österreichischen Befallsgebieten, aber auch Beobachtungen aus dem Ausland (IMDORF et al., 1987 ; Liebig, 1986 ; Herold, 1986) zeigen, daß sich die Milbenpopulationen in Völkern eines Bienenstandes oft unterschiedlich stark entwickeln. Die Bienenvölker zeigen ebenfalls eine unterschiedliche Belastbarkeit (BRETSCHKo, 1987 ; unveröffentliche Ergebnisse des Instituts für Bienenkunde). Die Anzahl produzierter Nachkommen pro befallener Brutzelle unterliegt ebenfalls großen Schwankungen.

In Uruguay (Rutrner F. und G. Marx, 1984) aber auch in Jugoslawien (Sulimanovic et al., 1986) zeigt sich ein Rückgang der Fertilität von Varroaweibchen auf Arbeiterinnenbrut. In Jugoslawien waren sogar innerhalb eines Standes beträchtliche Unterschiede feststellbar, die sich durch gezielte Auslese möglicherweise sogar noch verstärken lassen.

Um zu klären, welchen Einfluß der Befallsgrad der Völker auf die Vermehrungsfähigkeit der Milbe hat, wurden im Herbst 1986 an 33 institutseigenen Bienenvölkern an zwei Standorten Untersuchungen durchgeführt.

\section{MATERIAL UND METHODE}

Die untersuchten Bienenvölker von Apis mellifera carnica standen im nicderösterreichischen Voralpenland (Miesenbach) bzw. im Grenzgebiet des pannonischen Klimabereiches (Klosterneuburg). Der Stand in Klosterneuburg bestand zum Untersuchungszeitpunkt im September 1986 aus einer Gruppe von 18 Völkern. Dieser Stand wurde seit 1983, dem Zeitpunkt der natürlichen Infektion mit der Varroamilbe noch nie mit Medikamenten behandelt und weist durch die mitunter hohen Verluste im Lauf der Jahre stark schwankende Völkerzahlen auf.

Der Stand in Miesenbach bestand aus 13 normal geführten Wirtschaftsvölkern, die seit 1984 im Herbst mit Medikamenten behandelt worden sind.

Bei gewissen Fragestellungen (z.B. Abhängigkeit des Brutbefalls vom Entwicklungsstadium, Anteil der Mchrfachparasitierungen u.a.) wurden zwei weitere starkbefallene, aber bercits zusammenbrechende Völker (PI, 18) von zwei anderen Standorten mitausgewertet.

Aus jedem Volk wurde ein gedeckeltes Brutwabenstück entnommen. Dabei wurde darauf geachtet, daß der Großteil der Zellen dieses Stückes Puppen mit dunklen Augen beeinhaltete, soferne solche vorhanden waren. Bei fünf Völkern waren auf den vorhandenen Brutwaben entweder keine Stadien PAD-SR vorhanden oder es wurden pro Wabenstück weniger als 5 Zellen dieser Stadien gefunden. Die 
TAB. 1. - Entwicklungschema der Bienenpuppen (nach S.C. JAY, 1962 erweitert. Exakte Diagnosemerkmale siehe JAY.) und Schema zur Ermittlung der Fortpflanzungsbilanz

TABL. 1. - Schedule for estimation of reproduction balance

\begin{tabular}{|c|c|c|c|c|c|c|c|c|}
\hline $\begin{array}{c}\text { Stadium } \\
\text { Stage }\end{array}$ & $\begin{array}{c}\text { Tage nach } \\
\text { Ver- } \\
\text { puppung } \\
\text { Days after } \\
\text { pupation }\end{array}$ & $\begin{array}{l}\text { Tage bis } \\
\text { Schlupf } \\
\text { Days to } \\
\text { cmergence }\end{array}$ & Egg & $\begin{array}{c}\text { Proto- } \\
\text { nymphe } \\
\text { Proto- } \\
\text { nymph }\end{array}$ & $\begin{array}{c}\text { Deuto- } \\
\text { nymphe } \\
\text { Deuto- } \\
\text { nymph }\end{array}$ & $\begin{array}{l}\text { Jung- } \\
\text { milbe } \\
\text { Young } \\
\text { mite }\end{array}$ & $\begin{array}{c}\text { Männl. } \\
\text { Varroa- } \\
\text { larve } \\
\text { Male Varroa } \\
\text { larva }\end{array}$ & $\begin{array}{c}\text { Männl. } \\
\text { Varroa- } \\
\text { ei } \\
\text { Male Varroa } \\
\text { egg }\end{array}$ \\
\hline SM/VP & 0 & $10-12$ & + & + & 1 & 1 & + & + \\
\hline PAW & 1 & 9 & + & + & 1 & 1 & + & + \\
\hline PAHR & 2 & 8 & + & + & 1 & 1 & + & + \\
\hline PAR & 3 & 7 & + & + & 1 & 1 & + & + \\
\hline PAD - & 4 & 6 & - & + & 1 & 1 & + & + \\
\hline PAD & 5 & 5 & - & + & + & 1 & + & - \\
\hline PAD + & 6 & 4 & - & - & + & + & + & - \\
\hline PTD & 7 & 3 & - & - & + & + & + & - \\
\hline PTD + & 8 & 2 & - & - & + & + & - & - \\
\hline SR & 9 & 1 & - & - & - & + & - & - \\
\hline
\end{tabular}

SM $/ \mathrm{PP}=$ Streckmade, Vorpuppe. Stretched larva/prepupa.

PAW = Puppe Augen weils. pupa white eyes.

PAHR $=$ Puppe Augen hellrosa. pupa eyes slightly pink.

PAR = Puppe Augen rosa. pupa eyes pink.

PAD = Puppe Augen dunkel $(\mathrm{PAD}-$ bis PAD +$)$. pupa eyes dark (PAD - to PAD +).

PTD = Puppe Thorax dunkel (PTD bis PTD + ). pupa thorax dark (PTD to PTD + ).

SR = Biene schlupfreif, d.h. Imaginalhäutung bereits vollzogen. pupal moult complete.

$+\quad=$ Varroa kann sich fertigentwickeln und Begattung vollziehen. varroa can complete development and mate.

$=$ Varroa kann Entwicklung vor dem Schlupf der Biene nicht beenden. uncomplete development until emergence of bee.

$=$ entsprechendes Varroa-Entwicklungsstadium nicht $\mathrm{zu}$ crwarten. equivalent stage of varroa is not to be expected.

Brutwabenstücke umfaßten jeweils zirka 100 bis 150 Zellen. In sieben Fällen lag die Zahl untersuchter Zellen zwischen 40 und 100 . Vom zusammenbrechenden Volk 168 wurden alle 520 vorhandenen Brutzellen ausgewertet. Eine detaillierte Aufstellung der Zcllzahlen für jedes Entwicklungsstadium findet sich in Tab. 3-5. Nach der Entnahme wurde das Wabenstück tiefgefroren und im Labor unter Zuhilfenahme einer Kaltlichtquelle, die auch den Zellgrund gut ausleuchtete, auf Milben und ihre Nachkommen untersucht.

Die Entwicklungsstadien der Bienen wurden entsprechend Tab. 1 in 10 Stufen eingeteilt. Berücksichtigt wurden Färbung der Augen, Pigmentierung, Chitinisierung und andere Merkmale. Das Alter der Puppen wurde entsprechend den Angaben von $\mathrm{J}_{\mathrm{AY}}$ (1962 und 1963) dem jeweiligen Entwicklungsstadium 7uorerdnet 
TAB. 2. - Bienen- und Brutbefall mit Varroamilben sowie Überwinterung der Versuchsvölker TABL. 2. - Bee and brood infestation with Varroa mites and success of hibernation of test colonies

\begin{tabular}{|c|c|c|c|c|c|c|c|c|}
\hline $\begin{array}{l}\text { Volk } \\
\text { Col. }\end{array}$ & $\begin{array}{l}\text { Ort } \\
\text { Loc. }\end{array}$ & $\begin{array}{c}\text { Bienen } \\
\text { Bees }\end{array}$ & $\begin{array}{c}\text { Varroa } \\
\text { Varroa }\end{array}$ & $\begin{array}{c}\% \\
\text { Befall } \\
\% \text { bee } \\
\text { infest. }\end{array}$ & $\begin{array}{c}\text { Summe } \\
\text { Zellen } \\
\text { Sum } \\
\text { cells }\end{array}$ & $\begin{array}{c}\text { Bef. } \\
\text { Z. } \\
\text { Inf. } \\
\text { cells }\end{array}$ & $\begin{array}{c}\% \\
\text { Befall } \\
\% \text { brood } \\
\text { infest. }\end{array}$ & $\begin{array}{l}\text { Über- } \\
\text { wint. } \\
\text { Hiber- } \\
\text { nation }\end{array}$ \\
\hline $\begin{array}{r}80 \\
140 \\
459 \\
465 \\
502 \\
514 \\
516 \\
522 \\
533 \\
537 \\
542 \\
543 \\
549\end{array}$ & $\begin{array}{l}\mathrm{M} \\
\mathrm{M} \\
\mathrm{M} \\
\mathrm{M} \\
\mathrm{M} \\
\mathrm{M} \\
\mathrm{M} \\
\mathrm{M} \\
\mathrm{M} \\
\mathrm{M} \\
\mathrm{M} \\
\mathrm{M} \\
\mathrm{M}\end{array}$ & $\begin{array}{l}287 \\
181 \\
\\
323 \\
213 \\
\\
371 \\
\\
235 \\
171 \\
279\end{array}$ & $\begin{array}{r}83 \\
142 \\
48 \\
\\
109 \\
17 \\
\\
107 \\
\\
72 \\
40 \\
76\end{array}$ & $\begin{array}{c}36 \\
\text { n.e. } \\
49,5 \\
26,5 \\
\text { n.e. } \\
33,7 \\
7,9 \\
\text { n.e. } \\
28,8 \\
\text { n.e. } \\
30,6 \\
23,3 \\
27,2\end{array}$ & $\begin{array}{r}113 \\
115 \\
109 \\
112 \\
109 \\
103 \\
165 \\
123 \\
109 \\
94 \\
131 \\
118 \\
116\end{array}$ & $\begin{array}{l}31 \\
43 \\
68 \\
65 \\
51 \\
60 \\
41 \\
64 \\
27 \\
37 \\
52 \\
65 \\
32\end{array}$ & $\begin{array}{l}27,43 \\
37,39 \\
62,39 \\
58,04 \\
46,79 \\
58,25 \\
24,85 \\
52,03 \\
24,77 \\
39,36 \\
39,69 \\
55,08 \\
27,59\end{array}$ & $\begin{array}{l}+ \\
+ \\
- \\
+ \\
+ \\
- \\
+ \\
- \\
- \\
+ \\
+ \\
+ \\
+\end{array}$ \\
\hline $\begin{array}{l}\overrightarrow{\mathrm{x}}= \\
\mathrm{s}=\end{array}$ & $\mathbf{M}$ & & & $\begin{array}{l}27,57 \\
11,1\end{array}$ & & & $\begin{array}{l}42,19 \\
13,80\end{array}$ & \\
\hline $\begin{array}{l}436 \\
441 \\
462 \\
524 \\
525 \\
528\end{array}$ & $\begin{array}{l}\mathrm{K} \\
\mathrm{K} \\
\mathrm{K} \\
\mathrm{K} \\
\mathrm{K} \\
\mathrm{K}\end{array}$ & $\begin{array}{l}213 \\
256 \\
221 \\
301 \\
350 \\
120\end{array}$ & $\begin{array}{r}75 \\
82 \\
58 \\
85 \\
166 \\
9\end{array}$ & $\begin{array}{l}35,2 \\
32 \\
26,2 \\
28,2 \\
47,4 \\
7,5\end{array}$ & $\begin{array}{r}46 \\
124 \\
114 \\
108 \\
122 \\
155\end{array}$ & $\begin{array}{l}35 \\
74 \\
73 \\
86 \\
77 \\
65\end{array}$ & $\begin{array}{l}76,09 \\
59,68 \\
64,04 \\
79,63 \\
63,11 \\
41,94\end{array}$ & $\begin{array}{l}+ \\
- \\
- \\
- \\
- \\
-\end{array}$ \\
\hline $\begin{array}{l}\overline{\mathrm{x}}= \\
\mathrm{s}=\end{array}$ & K & & & $\begin{array}{l}33,60 \\
13,1\end{array}$ & & & $\begin{array}{l}67,88 \\
13,40\end{array}$ & \\
\hline $\begin{array}{r}22 \\
90 \\
120 \\
168 \\
454 \\
463 \\
483 \\
488 \\
494 \\
521 \\
531 \\
538\end{array}$ & $\begin{array}{l}\text { A } \\
\text { A } \\
\text { A } \\
\text { A } \\
\text { A } \\
\text { A } \\
\text { A } \\
\text { A } \\
\text { A } \\
\text { A } \\
\text { A } \\
\text { A }\end{array}$ & $\begin{array}{l}209 \\
147 \\
143 \\
296 \\
324 \\
157 \\
340 \\
267 \\
233 \\
198 \\
186 \\
289\end{array}$ & $\begin{array}{r}37 \\
9 \\
15 \\
283 \\
54 \\
28 \\
131 \\
66 \\
38 \\
61 \\
18 \\
31\end{array}$ & $\begin{array}{r}17,7 \\
6,1 \\
10,5 \\
95,6 \\
16,7 \\
17,8 \\
38,5 \\
24,7 \\
16,3 \\
30,8 \\
9,7 \\
10,7\end{array}$ & $\begin{array}{r}49 \\
175 \\
182 \\
520 \\
81 \\
119 \\
135 \\
132 \\
157 \\
72 \\
51 \\
167\end{array}$ & $\begin{array}{r}20 \\
58 \\
90 \\
328 \\
62 \\
81 \\
62 \\
71 \\
108 \\
20 \\
21 \\
48\end{array}$ & $\begin{array}{l}40,82 \\
33,14 \\
49,45 \\
63,08 \\
76,54 \\
68,07 \\
45,93 \\
53,79 \\
68,79 \\
27,78 \\
41,18 \\
28,74\end{array}$ & $\begin{array}{l}- \\
- \\
- \\
- \\
+ \\
- \\
- \\
- \\
- \\
- \\
- \\
+\end{array}$ \\
\hline $\begin{array}{l}\overline{\mathrm{x}}= \\
\mathrm{s}=\end{array}$ & A & & & $\begin{array}{l}32,48 \\
24,2\end{array}$ & & & $\begin{array}{l}46,62 \\
16,40\end{array}$ & \\
\hline $\begin{array}{l}\overrightarrow{\mathrm{x}}= \\
\mathrm{s}=\end{array}$ & $\mathbf{K}+\mathbf{A}$ & & & $\begin{array}{l}26,2 \\
20,9\end{array}$ & & & $\begin{array}{l}54,50 \\
16,60\end{array}$ & \\
\hline $\begin{array}{l}18 \\
\mathrm{Pl}\end{array}$ & & & & $\begin{array}{l}\text { n.e. } \\
75\end{array}$ & $\begin{array}{r}65 \\
151\end{array}$ & $\begin{array}{l}49 \\
58\end{array}$ & $\begin{array}{l}75,38 \\
38,41\end{array}$ & - \\
\hline
\end{tabular}

$\mathbf{M}=$ Miesenbach $; \quad \mathrm{K}=$ Klosterneuburg-Wirtschaftsvolk (producing colony); $\mathrm{A}=$ Klosterneuburg-Ableger (nucleus colony) $:$ Brutz. $=$ Brutzellen $;$ bef. $\mathrm{Z} .=$ befallene Zellen $;$ n.e. $=$ nicht ermittelt $($ not investigated) Uberwint. = Überwinterung ; $+=$ lebend $;-=$ tot 
Dic Milben wurden in Altmilben, Jungmilben, Eier, Proto- und Deutonymphen eingetcilt. Anhand eines Zeitschemas, das auf den von IFANTIDIS (1983) beziehungsweise WeIss (1986) gefundenen Entwicklungszeiten der Varroa bzw. der Biene basiert (Tab. 1), erfolgte zur Ermittlung der Fortpflanzungsbilanz eine Abschätzung, ob sich das entsprechende Milbenstadium noch zu cinem fortpflanzungsfähigen Weibchen bzw. Männchen entwickeln kann, oder nicht.

Zur Ermittlung der Nachkommensrate der Varroamilben wurden nur Brutstadien PAD-SR ausgewählt, da sich ab diesem Zeitpunkt eventuell noch abgelegte Eier nicht mehr zu fortpflanzungsfähigen Milben entwickeln können, wenn man dic in Tab. 1 und Abb. 6 angeführten Entwicklungszeiten für Männchen und Weibchen berücksichtigt.

Wenn in den Zellen neben weiblichen Deutonymphen noch keine erwachsenen Männchen zu finden waren, wurde beim Vorhandensein von weiteren Protonymphen angenommen, daB sich von den vorhandenen Protonymphen cine zu einem Männchen entwickeln wird. Die Anzahl eingedrungener Muttermilben wurde dabei mitberücksichtigt. Die Protonymphen wurden nicht nach Geschlechtern unterschieden. Die Anzahl der in jede Zelle eingedrungenen Muttermilben sowie deren Nachkommen wurden für jede Zelle getrennt erfaßt, um cine eventuclle Abhängigkeit der Nachkommensrate vom Parasitierungsgrad der Einzelzelle (erfaßt als 1, 2, 3, 4, 5, 6, 7 oder mehr als 7 Muttermilben pro Zelle) feststellen zu können. Die Bienenproben stammten von den Waben, aus denen auch die Brutwabenstücke entnommen wurden. Der Probenumfang lag jeweils zwischen 120 und 370 Bienen.

Dic Bienen wurden ticfgeküht und dic Zahl anhaftender Milben mittels cines Rüttelsicbes unter dauerndem Wasserdurchflul3 ermittelt.

Eine Untersuchung der Einzelbienen auf parasitierende Varroamilben wurde nicht durchgeführt.

Statistische Auswertung :

Alle Auswertungen erfolgten am Land- und forstwirtschaftlichen Rechenzentrum des Bundesministeriums für Land- und Forstwirtschaft mit dem Statistikpaket SPSS.

\section{ERGEBNISSE}

\subsection{Befall der Bienen mit Varroamilben}

Die Einzelwerte des Bienenbefalles (Anzahl Varroamilben/Bienenzahl, ausgedrückt in Prozent) schwankten zwischen den Völkern sehr stark. Die Mittelwerte zeigten jedoch keine großen Unterschiede (Tab. 2).

Eine statistische Auswertung ergab keine signifikanten Unterschiede zwischen den Standorten Klosterneuburg und Miesenbach (Kruskal-Wallis 1-Weg Rangvarianzanalyse ; $\mathrm{p}=0,258$, n.s.).

\subsection{Befall der Bienenbrut mit Varroamilben}

3.2.1. Abhängigkeit des Befallsgrades vom untersuchten Entwicklungsstadium der Bienen (Tab. 3-6)

Um die starke Abhängigkeit des Befallsgrades vom jeweiligen Entwicklungsstadium besser erfassen zu können, wurden die Bienenlarven entsprechend ihrem Verpuppungszustand bzw. ihrer Augenfärbung laut dem Schema in Tab. 1 eingeteilt. 


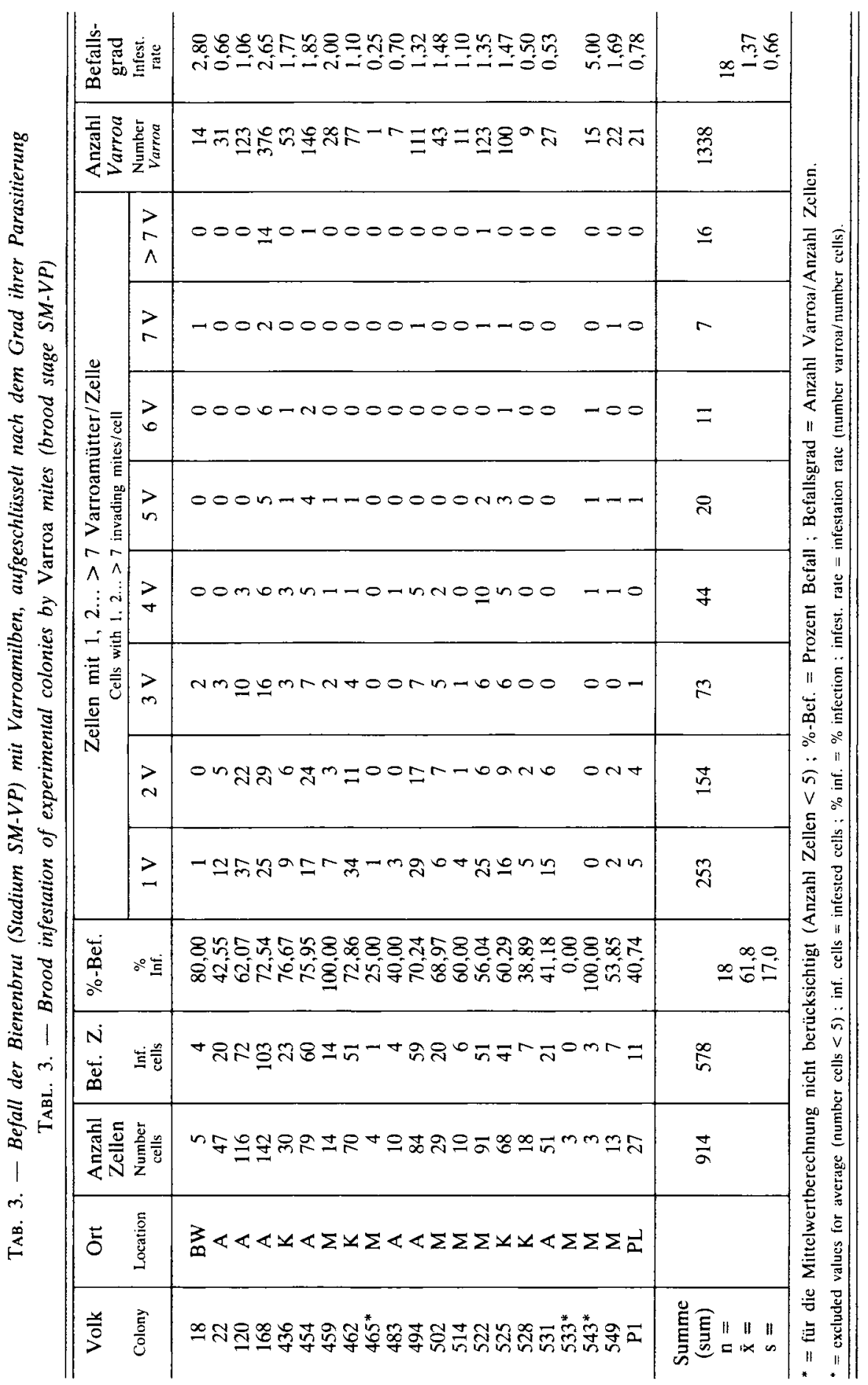




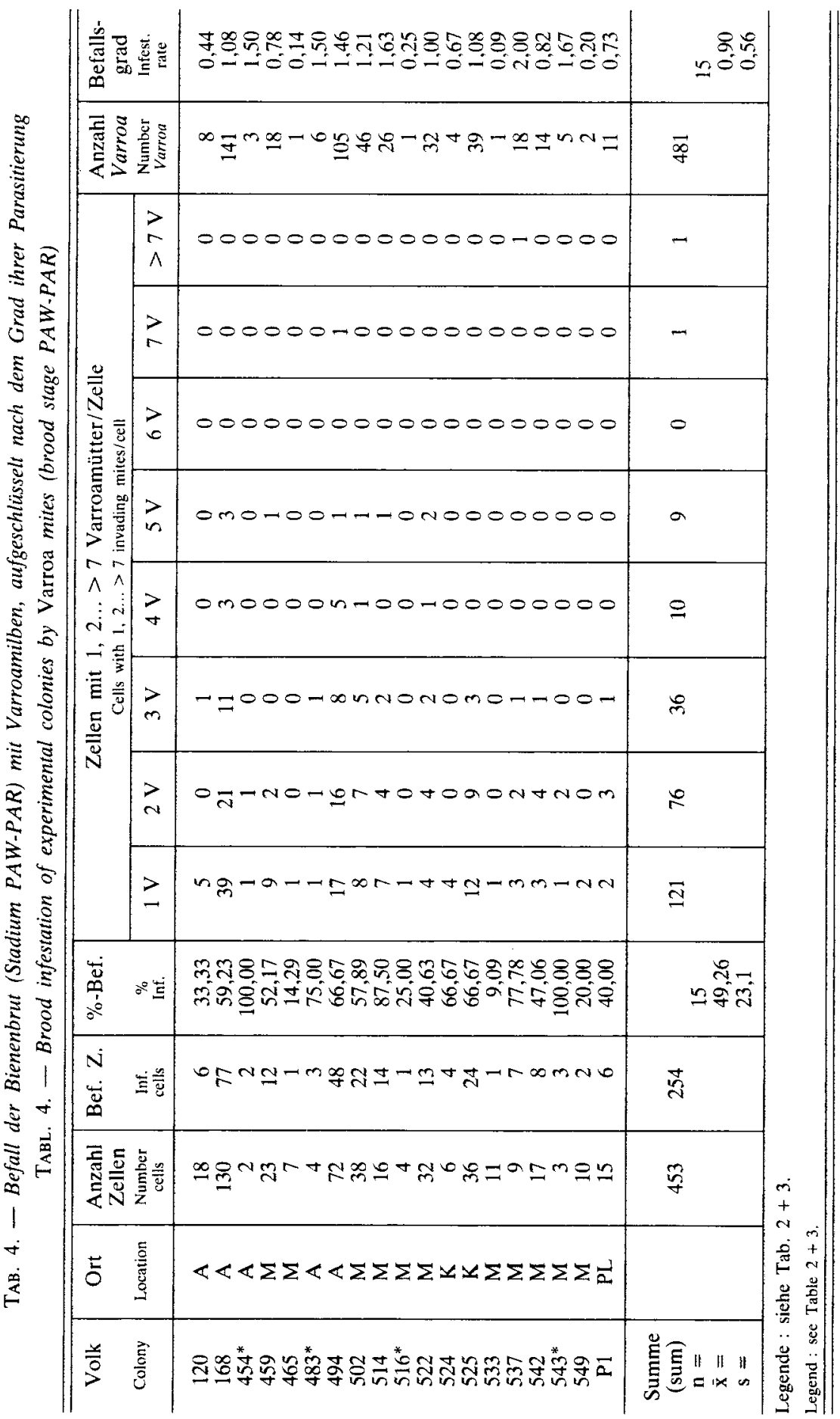




\begin{tabular}{|c|c|c|c|}
\hline$\frac{z}{z}$ & 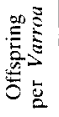 & 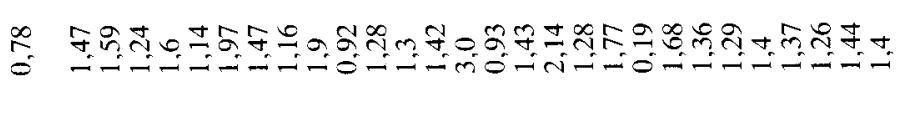 & 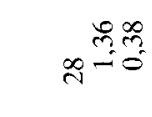 \\
\hline \multicolumn{2}{|c|}{ 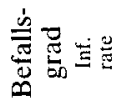 } & 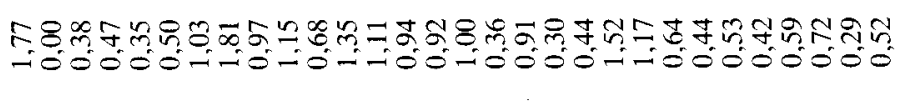 & 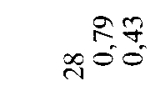 \\
\hline \multicolumn{2}{|c|}{ 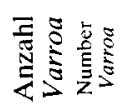 } & 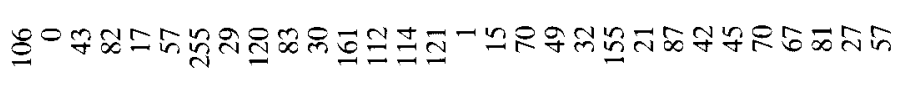 & $\underset{g}{\stackrel{g}{a}}$ \\
\hline \multirow{8}{*}{ 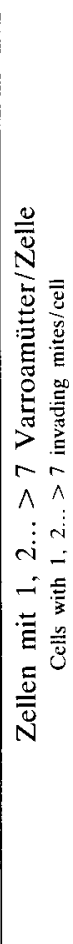 } & $\stackrel{>}{\wedge}$ & $000000-100000000000000000000000$ & - \\
\hline & $>$ & N00000000000000000000000000000 & $\mathrm{N}$ \\
\hline & b & $0000000-000-1+10000000000000000$ & in \\
\hline & $>$ & 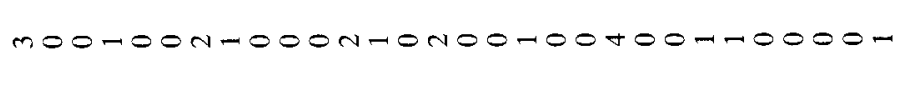 & ๙ิ \\
\hline & $\begin{array}{ll}> \\
\end{array}$ & 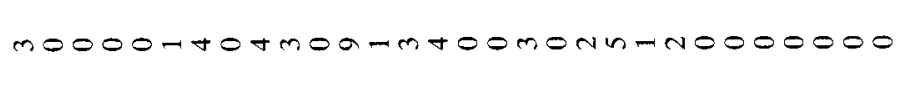 & f \\
\hline & 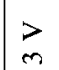 & 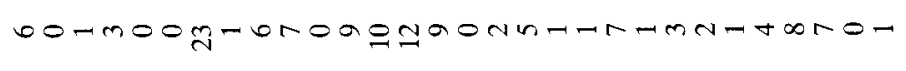 & 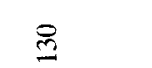 \\
\hline & $\vec{n}$ & 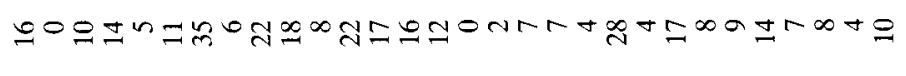 & $\vec{m}$ \\
\hline & $>$ & 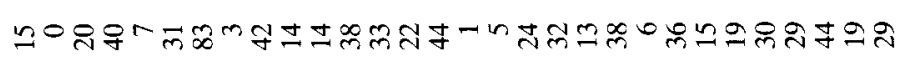 & $\frac{\pi}{8}$ \\
\hline$\frac{\dot{D}}{\grave{m}}$ & $\therefore$ & 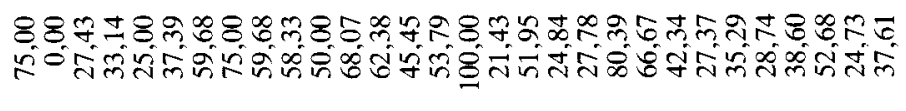 & so \\
\hline $\begin{array}{l}N \\
\dot{D}\end{array}$ & $\rightleftarrows \stackrel{0}{\Xi}$ & 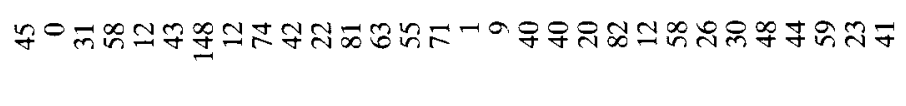 & $\stackrel{\mathscr{R}}{\mathfrak{Z}}$ \\
\hline 苛 & 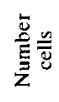 & 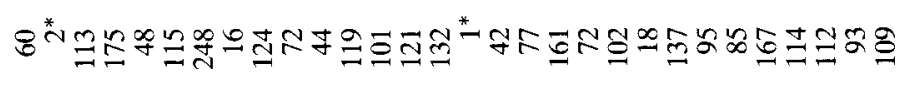 & $\underset{\substack{n \\
\infty}}{\infty}$ \\
\hline$\frac{1}{3}$ & $\frac{\vec{c}}{8}$ & 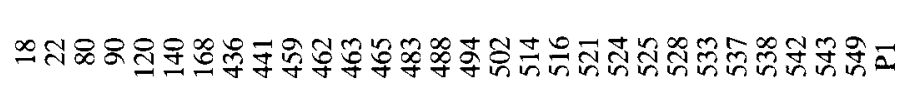 & 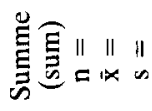 \\
\hline
\end{tabular}




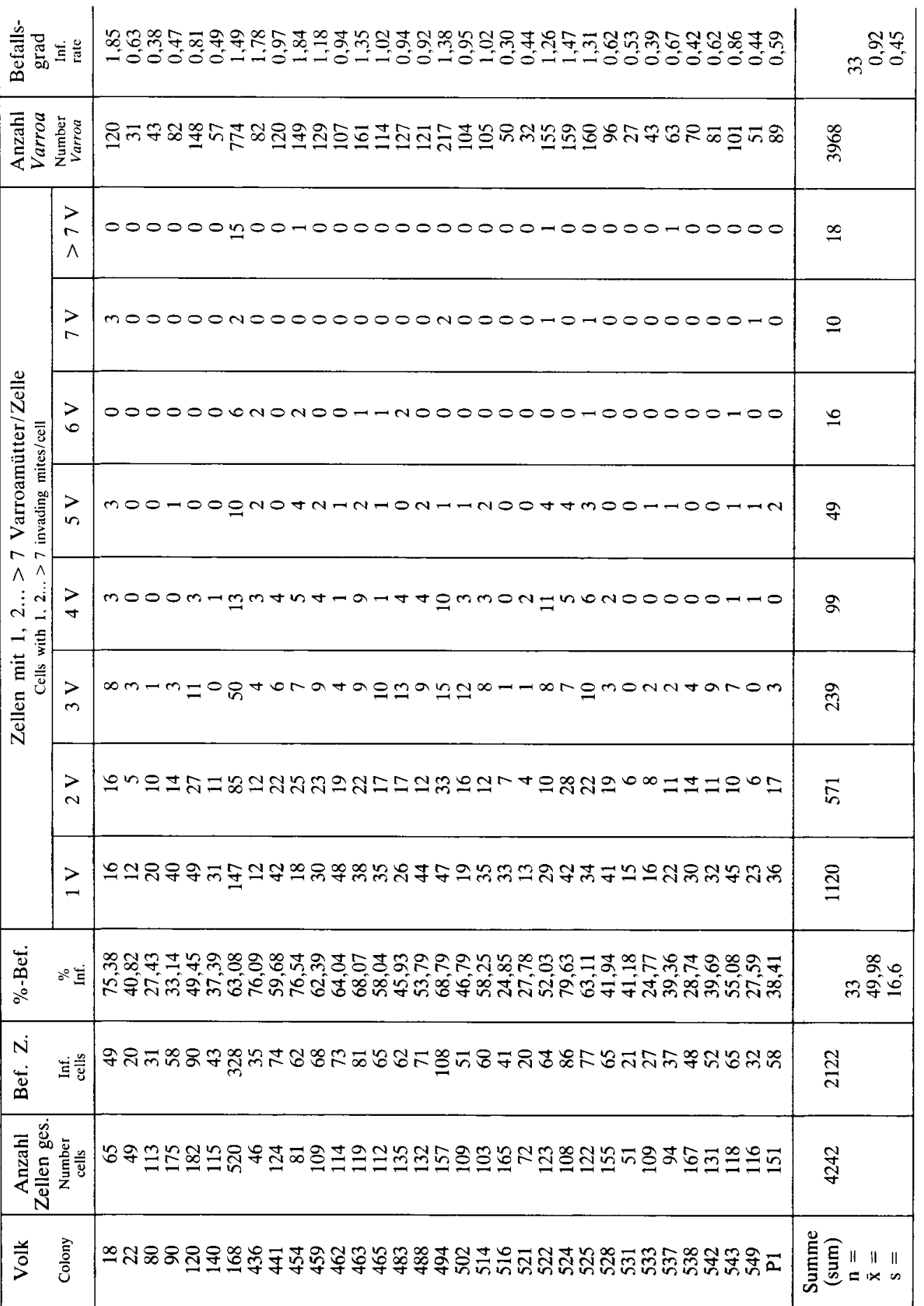


Als Rekordwert wurden 18 eingedrungene Varroamilben in einer Arbeiterinnenzelle mit SM/VP gezählt !

Vom Streckmadenstadium bis zum Schlüpfen der Biene kommt es zu einer Abnahme des prozentuellen Brutbefalles um durchschnittlich 15 Prozent (Tab. 3 und 5). In Einzelfällen betrug die Differenz bis zu $48 \%$.

Ausgedrückt als Befallsgrad (= Anzahl Varroa/Anzahl Zellen) kommt es zu einem Rückgang von durchnittlich 1,37 (SM-VP) über 0,9 (PAW-PAR) auf 0,79 (PAD-SR).

3.2.2. Unterschiede zwischen den Standorten im mittleren Befall der Bienenbrut (SM - SR) mit Varroamilben

Die Unterschiede zwischen Wirtschaftsvölkern und Ablegern in Klosterneuburg (Tab. 2), ließen sich statistisch nicht absichern (Kruskal-Wallis 1-Weg Rangvarianzanalyse ; $\mathrm{p}=0,092$, n.s.). Zwischen den Standorten Miesenbach und Klosterneuburg bestand ein signifikanter Unterschied im mittleren Befallsgrad (Kruskal-Wallis 1-Weg Rangvarianzanalyse ; $\mathrm{p}=0,025$ ).

\subsubsection{Korrelation zwischen Bienen- und Brutbefall}

Mit steigendem Bienenbefall stieg auch der Brutbefall an. Es lieB sich aber zwischen dem prozentuellen Bienen- und Brutbefall kein gesicherter Zusammenhang nachweisen (Rangkorrelation nach Spearman, $\mathbf{n}=27$, rs $=0,2106$, n.s.).

3.3. Anteil befallener Zellen mit nur männlichen Nachkommen beziehungsweise ohne Varroa-Fortpflanzung (PAD-SR) (Tab. 7)

Im Durchschnitt $(\mathrm{n}=28$ Völker) war in $7 \%$ der befallenen Zellen keine Varroafortpflanzung (das heißt : keine Eiablage) zu beobachten. Die Minimalund Maximalwerte schwankten, jedoch von 0 bis 33 Prozent.

IfANTIDIS (1984) fand in 19 Prozent der Zellen keine Varroafortpflanzung.

Zwischen den Standorten Miesenbach und Klosterneuburg waren keine signifikanten Unterschiede zu beobachten (Kruskal-Wills 1-Weg Rangvarianzanalyse, $\mathrm{n}=27, \mathrm{p}=0,124$, n.s.).

Ausschließlich männliche Nachkommen (PAD-SR) waren im Durchschnitt bei $2,9 \%(n=28$ Völker, $s=3,7)$ der befallenen Zellen anzutreffen.

\subsection{Unterschiede zwischen den Völkern in der Zahl der Nachkommen pro} Varroa

Zwischen den Völkern traten starke Unterschiede in der Nachkommenzahl pro Varroa auf (Tab. 5). 


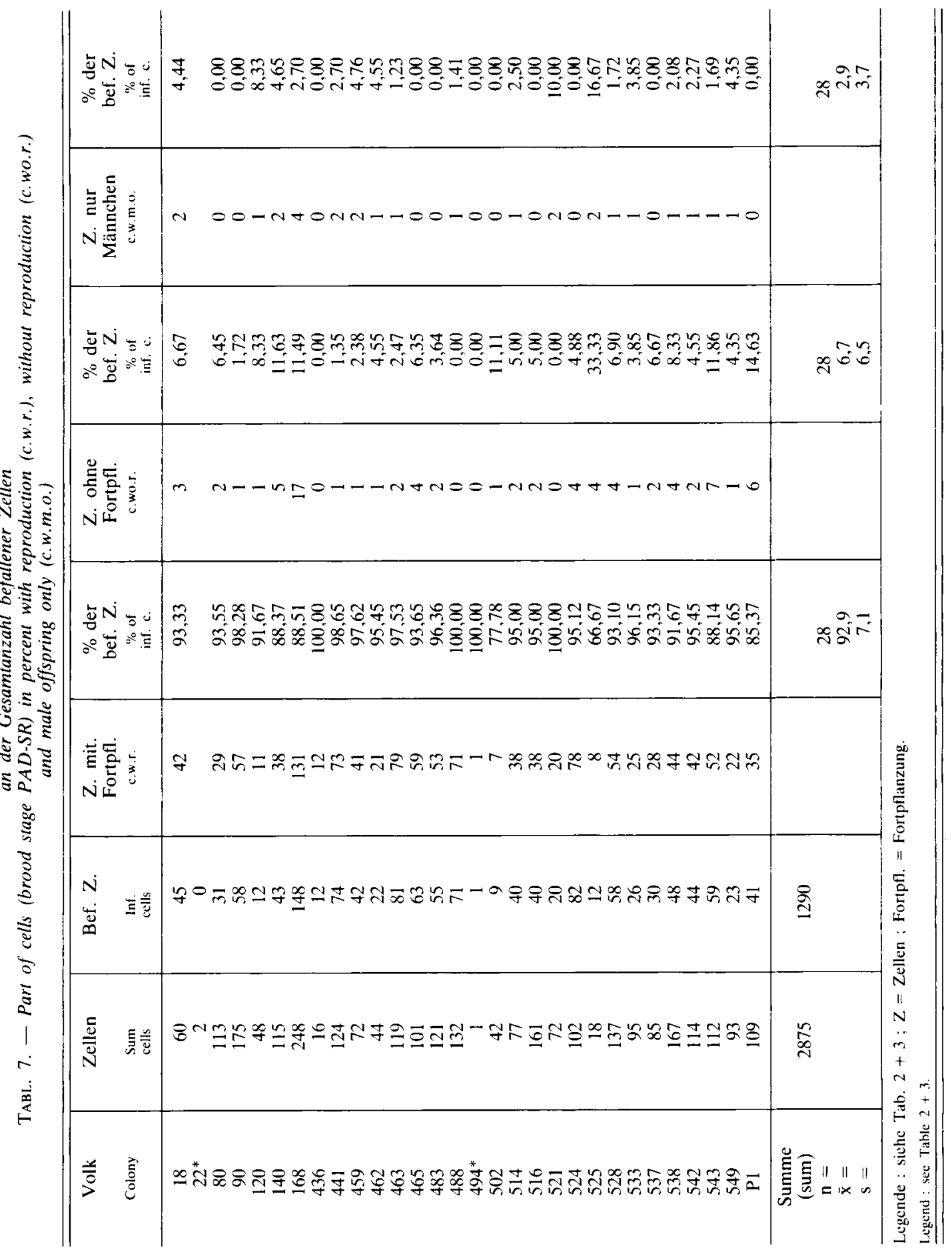


Signifikante Unterschiede zwischen den Standorten Miesenbach und Klosterneuburg (Kruskal-Wallis 1-Weg Rangvarianzanalyse, $\mathrm{p}=0,362$, n.s.) aber auch zwischen Wirtschaftsvölkern und Ablegern $(\mathrm{p}=0,257$, n.s.) ließen sich nicht feststellen.

Auf das Überleben der Völker im darauffolgenden Herbst/Winter hatten diese Unterschiede aber keinen erkennbaren Einfluß :

Mittelwert der toten Völker : 1,3 Nachkommen/Varroa

Mittelwert der überlebenden Völker : 1,5 Nachkommen/Varroa

Der Unterschied zwischen toten und überlebenden Völkern war nicht signifikant ( $t$-Test, $t=1,28$, n.s.). Es zeigt sich jedoch ein deutlicher Zusammenhang mit dem relativen Bienen- und Brutbefall (Tab. 2).

Die überlebenden Völker hatten einen deutlich geringeren Bienen- und Brutbefall als die toten Völker. Im Gegensatz dazu war die Nachkommensrate pro Varroa bei den überlebenden Völkern höher, als bei den toten, was sich sehr gut mit der in den Abb. 1 und 2 dargestellten negativen Korrelation zwischen Befallsgrad und Nachkommensrate deckt.

Zwischen Wirtschaftsvölkern und Ablegern bestanden in Klosterneuburg keine statistisch signifikanten Unterschiede in der Anzahl der Nachkommen pro Varroa (Kruskal-Wallis 1-Weg Rangvarianzanalyse, $\mathbf{n}=14, \mathbf{p}=\mathbf{0 , 2 5 7}$, n.s.).

3.5. Zusammenhang zwischen Bienen- und Brutbefall und der Anzahl der Nachkommen pro Varroa

Mit zunehmender Anzahl befallener Bienen bzw. Brutzellen in einem Bienenvolk, nimmt die Nachkommensrate pro eingedrungenem Varroaweibchen ab (s. Abb. 1 und Abb. 2). Die Rangkorrelation nach Spearman ergab für den Bienenbefall einen signifikanten ( $r s=-0,3508, n=28, \alpha=0,05$ ) und für den Brutbefall einen höchstsignifikanten Zusammenhang ( $\mathrm{rs}=-0,06382, \mathrm{n}=28, \alpha=0,001$ ).

\subsection{Abhängigkeit der Varroa-Vermehrungsbilanz pro Zelle vom} Parasitierungsgrad pro Zelle

Der prozentuelle Anteil von Zellen mit negativer Varroa-Vermehrungsbilanz (es schlüpfen pro Zelle weniger fortpflanzungsfähige Varroaweibchen, als eingedrungen sind) steigt höchstsignifikant an, wenn der Parasitierungsgrad pro Zelle zunimmt; Abb. 3 ; (Produkt-Moment Korrelation nach Pearson, $\mathrm{n}=112, \mathrm{r}=0,4598, \mathrm{p}<0,00000)$.

Der Anteil von Zellen mit positiver Varroa-Vermehrungsbilanz (es schlüp- 


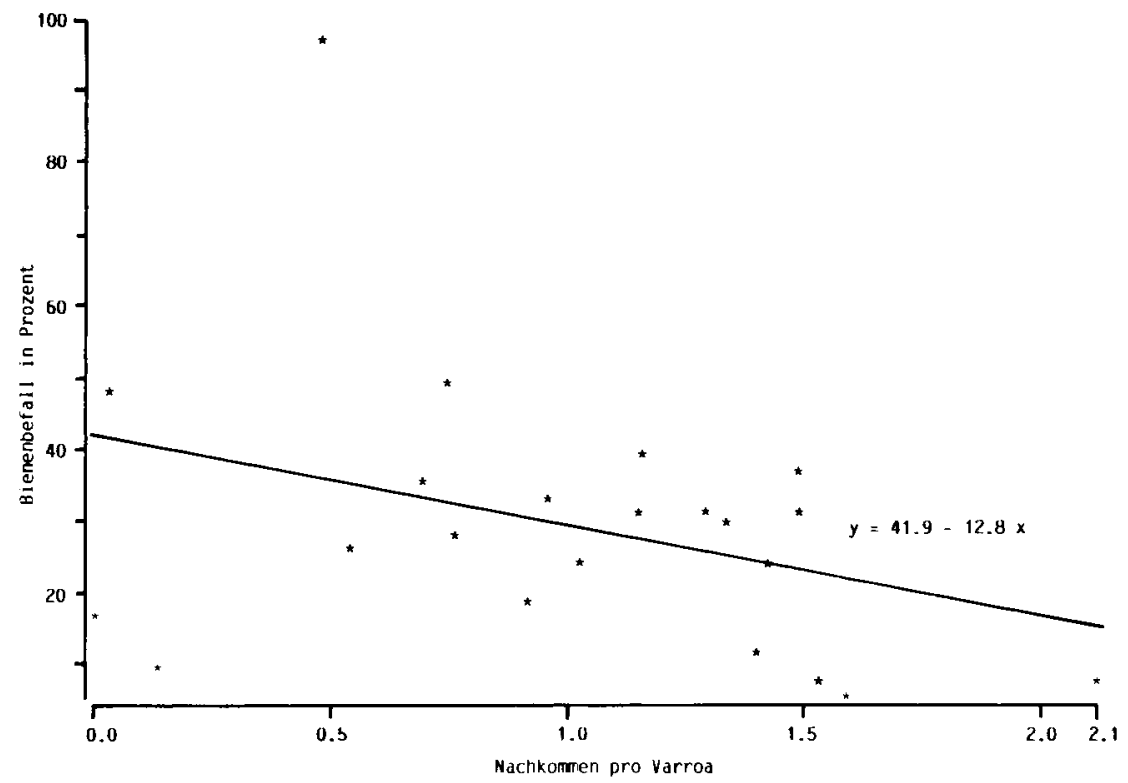

Авв. 1. - Zusammenhang zwischen dem Prozentsatz befallener Bienen und der Anzahl an Nachkommen pro Varroa.

horizontal : Nachkommen pro Varroa.

vertikal : Bienenbefall in Prozent.

FIG. 1. - Relation between bee infestation rate (as percentage) and offspring number per Varroa. horizontal : offspring per Varroa.

vertical : bee infestation rate (as percentage).

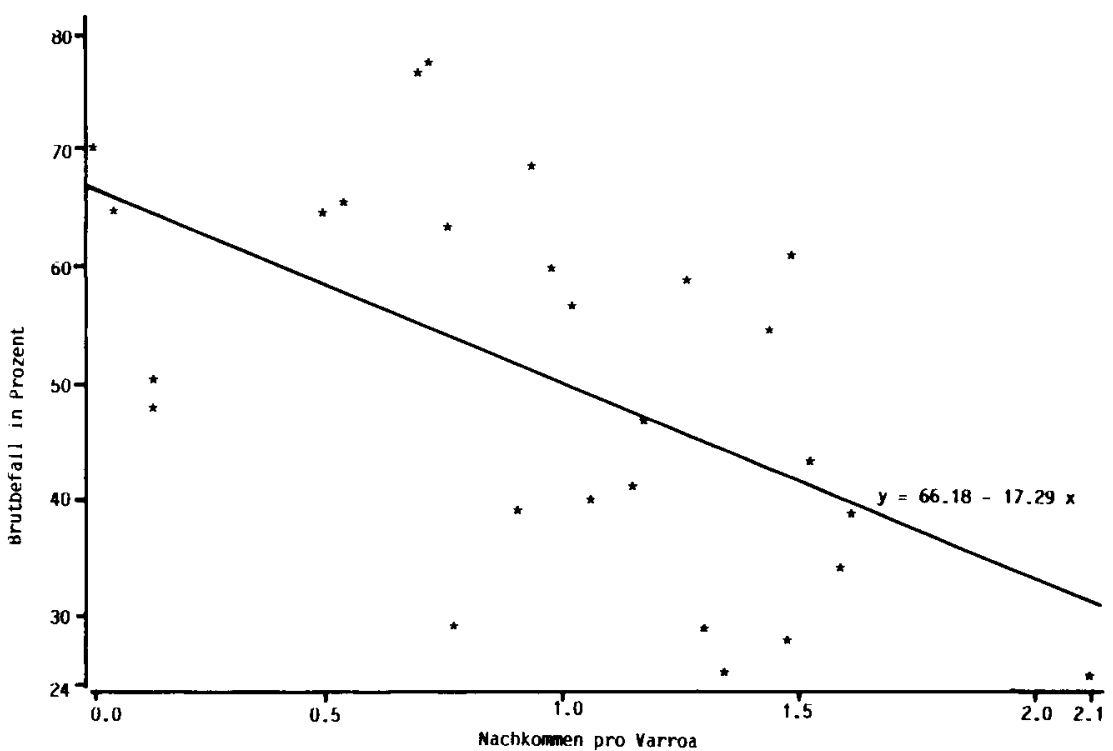

Aвв. 2. - Zusammenhang zwischen dem Prozentsatz befallener Brutzellen und der Anzahl von Nachkommen horizontal : Nachkommen pro Varroa.

vertikal : Brutbefall in Prozent.

FIG. 2. - Relation between brood infestation rate (as percentage) and offspring number per Varroa. horizontal : offspring per Varroa.

vertical : brood infestation rate (as percentage). 


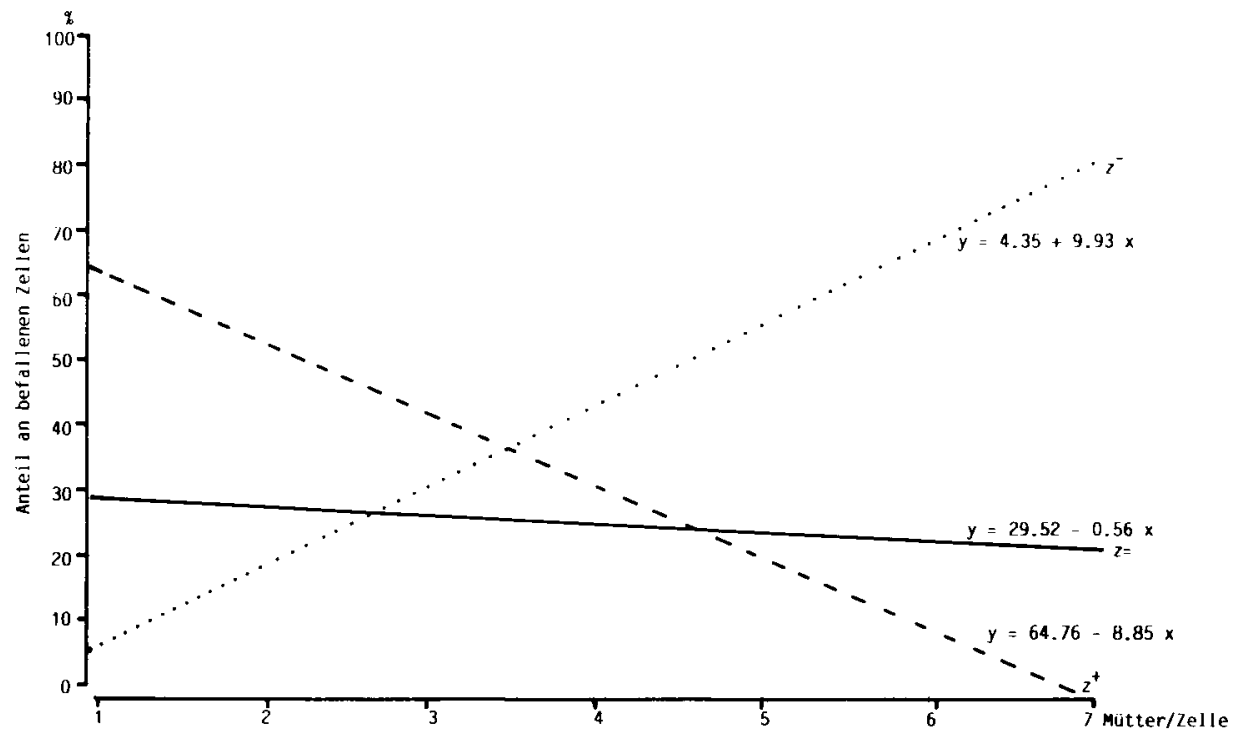

Авв. 3. - Abhängigkeit der Varroa-Vermehrungsbilanz pro Zelle vom Parasitierungsgrad. horizontal : Mütter pro Zelle.

vertikal : Anteil an befallenen Zellen in Prozent.

$z-=$ negative Bilanz.

$z+=$ positive Bilanz.

$\mathrm{z}==$ ausgeglichene Bilanz.

FIG. 3. - Varroa multiplication balance per cell depending on parasitization rate.

horizontal : invading mites per cell.

vertical : share of infested cells (as percentage).

$z-=$ negative balance

$z+=$ positive balance.

$\mathrm{z}=$ = equalized balance.

fen pro Zelle mehr fortpflanzungsfähige Varroaweibchen, als eingedrungen sind) fällt im Gegensatz dazu höchstsignifikant ab ; $(n=112, r=-0,4459$, $\mathrm{p}<0,00000)$.

Diese zwei Regressionsgeraden schneiden sich bei einem Parasitierungsgrad von 3,5 Müttern pro Zelle.

Der Anteil an Zellen mit positiver bzw. negativer Vermehrungsbilanz liegt dann bei 37 Prozent.

Der Widerspruch mit Abb. 5 ist nur scheinbar, wenn man berücksichtigt, daß in Abb. 3 nur die Vermehrungsbilanz pro Zelle (positiv, negativ, ausgeglichen ; ohne Berücksichtigung eines Überschusses oder Defizits an Nachkom- 
men) dargestellt ist. In Abb. 5 hingegen ist die Zahl der Nachkommen pro Varroa dargestellt, die als ein komplexes Ergebnis der Varroavermehrungsbilanz pro Zelle aufzufassen ist.

Der Anteil an Zellen mit ausgeglichener Vermehrungsbilanz (es entstehen pro Zelle gleich viele begattete weibliche Nachkommen, wie Muttermilben eingedrungen sind), zeigt mit zunehmendem Parasitierungsgrad eine leicht fallende, aber nicht signifikante Tendenz; $(n=112, r=-0,0307, p=0,37$, n.s.).

\subsection{Abhängigkeit einer Mehrfachparasitierung vom Brutbefall}

Mit steigendem Befall der Bienenbrut durch Varroa war ein höchstsignifikantes Ansteigen der Anzahl pro Zelle eingedrungener Varroaweibchen feststellbar (Abb. 4). Rangkorrelation nach Spearman: $r s=0,535, \quad n=29$, $\alpha=0,001$.

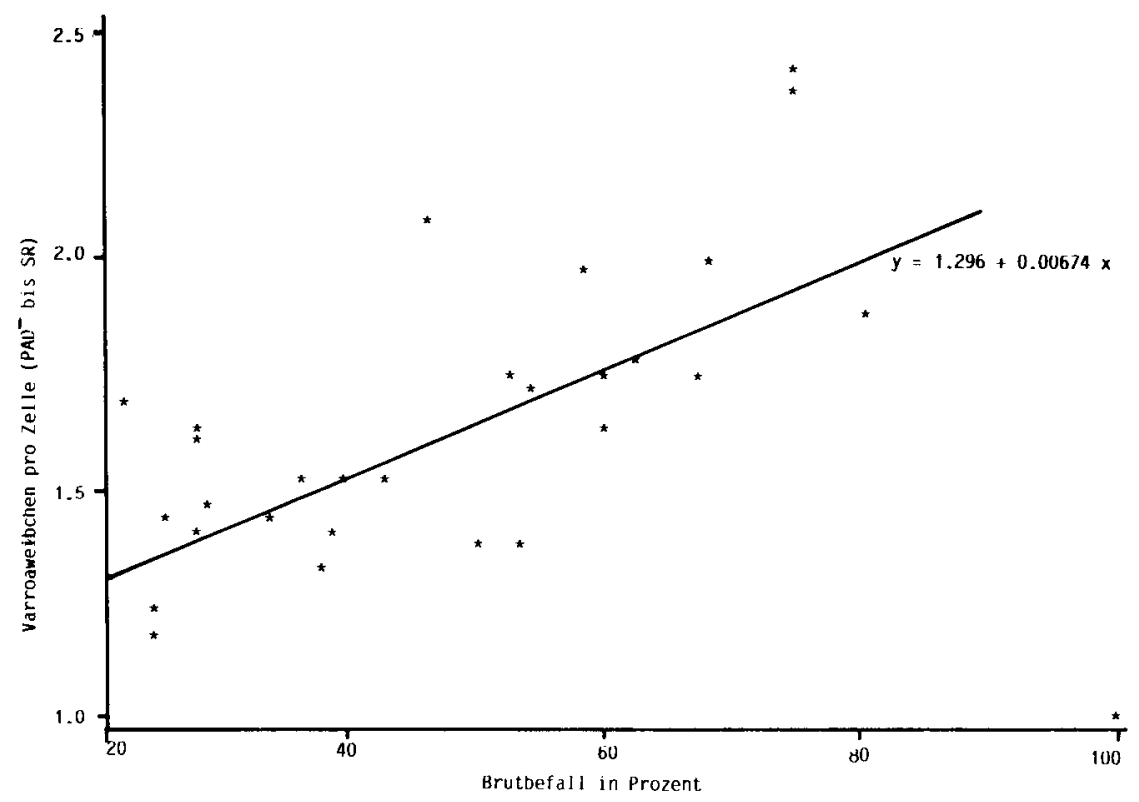

Aвв. 4. - Abhängigkeit einer Mehrfachparasitierung vom Brutbefall.

(Ausgewertete Brutstadien : PAD- bis SR)

horizontal : Brutbefall in Prozent.

vertikal : Varroamütter pro Zelle.

FIG. 4. - Relation between multiple parasitization of cells and brood infestation rate.

(Analysed brood stages : PAD- bis SR)

horizontal : brood infestation rate (as percentage).

vertical : invading mites per cell. 


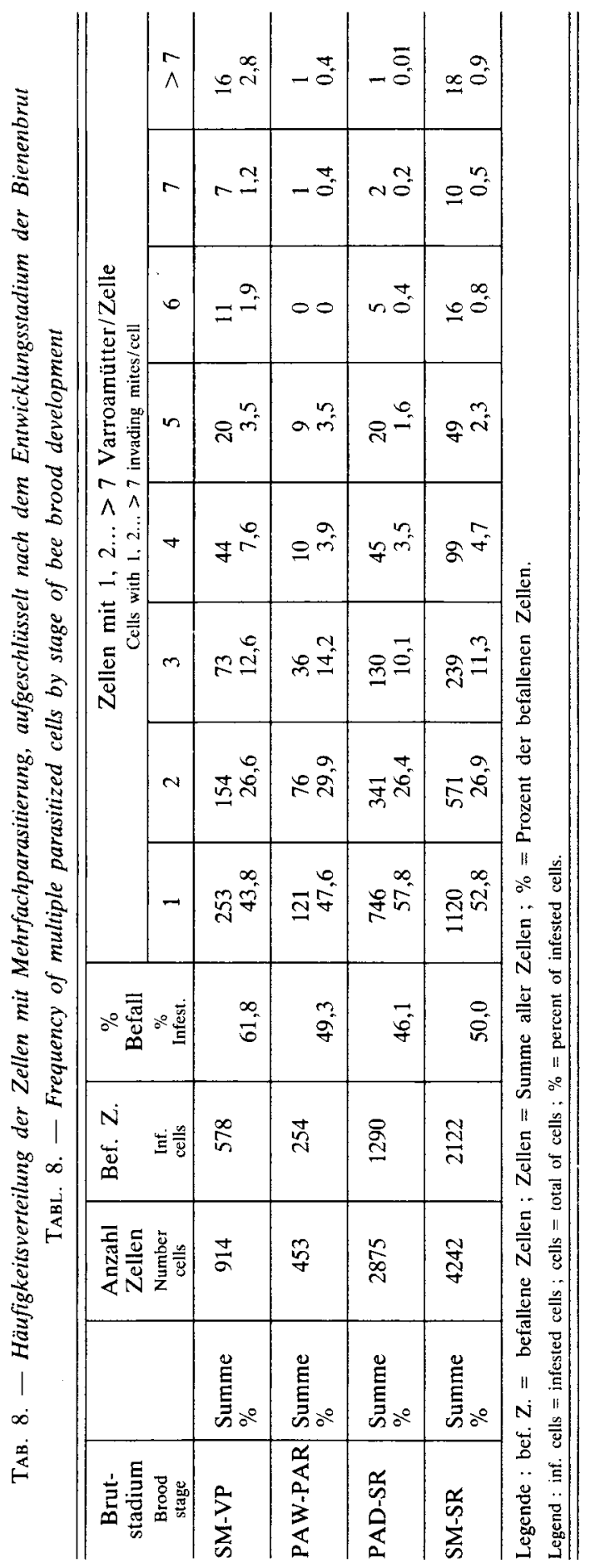


3.8. Prozentueller Anteil der Zellen mit 1, 2, 3, 4, 5, 6, 7, > 7 Varroa-Müttern pro Zelle an der Gesamtzahl befallener Zellen

Tab. 8 zeigt die Häufigkeitsverteilung der Parasitierungsgrade (= Mütter/ Zelle) der Einzelzellen für die untersuchten Entwicklungsstadien der Bienen.

Bezogen auf das Larvenstadium steigt der Anteil (in Prozent) an den befallenen Zellen bei einer Varroamutter/Zelle vom Stadium SM-VP bis zum Stadium PAD-SR an. Ab einem Parasitierungsgrad von vier Mütter/Zelle ist hingegen eine Abnahme festzustellen. Analog dazu nimmt auch die Anzahl der Nachkommen pro Varroa ab; (Abb. 5).

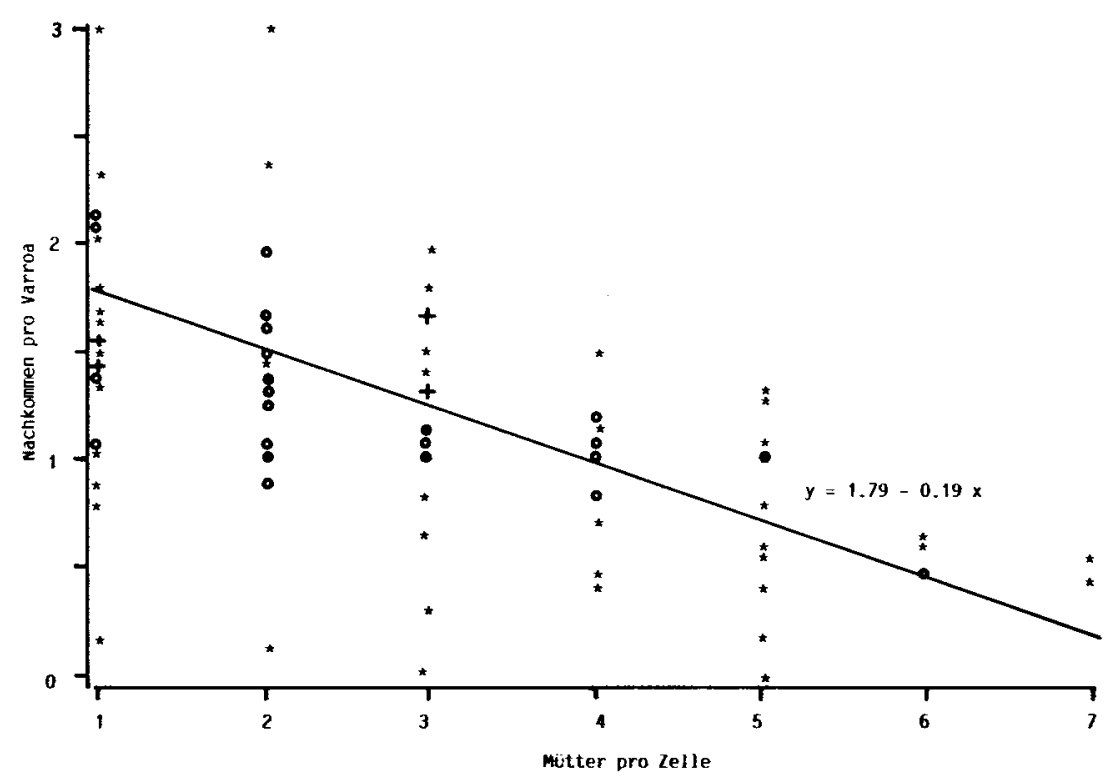

Aвв. 5. - Abhängigkeit der Nachkommensrate pro Varroa von der Anzahl eingedrungener Mütter pro Zelle. horizontal : Mütter pro Zelle.

vertikal : Nachkommen pro Varroa.

* $=1$ Wert.

$0=2$ Werte.

- $=3$ Werte.

$+=4$ Werte.

FIG. 5. - Relation between offspring rate per Varroa and number of invading mites per cell. horizontal : invading mites per cell.

vertical : offspring per Varroa.

$*=1$ value.

$0=2$ values.

- $=3$ values.

$t=4$ values. 


\subsection{Abhängigkeit der Nachkommensrate von der Anzahl pro Zelle} eingedrungener Varroaweibchen

Die Nachkommenzahl pro Varroa nimmt mit steigender Anzahl der Mütter pro Zelle höchstsignifikant ab; Abb. 5; (Produkt-Moment Korrelation nach Pearson, $\mathrm{n}=110, \mathrm{r}=-0,5534, \mathrm{p}=0,001)$.

$\mathrm{Ab}$ zirka 4 eingedrungenen Varroaweibchen pro Zelle entstehen im Durchschnitt weniger fortpflanzungsfähige weibliche Nachkommen pro Zelle, als Mütter eingedrungen sind.

Gemessen an der Gesamtzahl befallener Zellen, betrug der Anteil der Mehrfachparasitierungen mit 4 oder mehr Müttern pro Zelle im Herbst 1986 9,1 Prozent (Tab. 8).

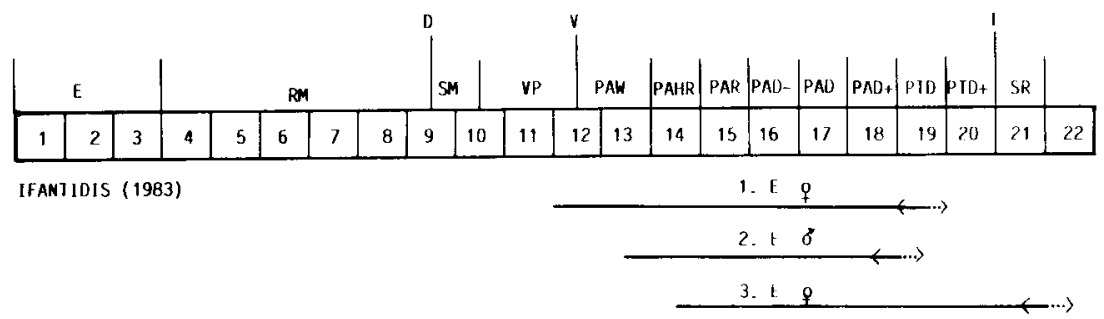

MOOSBECKHOFER et al.

$30 \times$ der Milben:

$30 \%$ of mites:

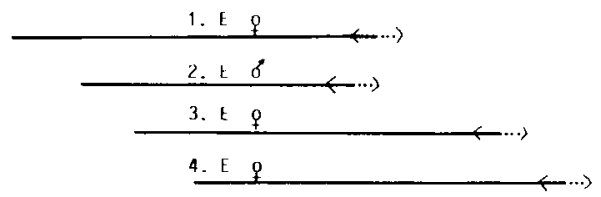

Aвв. 6. - Unterschiedlicher Beginn der Eiablage von Varroa jacobsoni Oud. bei Apis mellifera cecropia (IFANTIDIS, 1983) und Apis mellifera carnica, wie sie bei $30 \%$ der Milben beobachtet wurde.

Zeitpunkt für Verdeckelung, Verpuppung und Imaginalhäutung nach WeIss (1986).

Zeichenerklärung : siehe Tab. 1
RM $=$ Rundmade
$\mathrm{D}=$ Verdeckelung.
$\mathrm{V}=$ Verpuppung.
I = Imaginalhäutung.
$\mathbf{E}=\mathrm{Ei}$

Fig. 6. - Different beginning of oviposition by Varroa jacobsoni Oud. in Apis mellifera cecropia (IFANTIDIS, 1983) and Apis mellifera carnica like it was observed in $30 \%$ of mites.

Time of sealing, pupation and imaginal moult according to WEISs (1986)

Legend: Table 1

RM = coiled larva.

$\mathrm{D}$ = sealing of cell.

$\mathrm{V}=$ pupation.

I = imaginal moult.

$\mathrm{E}=$ Egg. 
3.10. Vorkommen von Varroa-Eiern bzw. -Larven in befallenen Zellen mit Streckmaden oder Vorpuppen

Bei $28,7 \%$ aller Streckmaden und Vorpuppen wurden bereits Eier und bei $1,9 \%$ auch Protonymphen der Varroamilbe gefunden (Tab. 9). Dies bedeutet, daß bei Apis mellifera carnica ein größerer Teil von Milben früher mit der Eiablage beginnt, als dies von Ifantidis (1983) bei Apis mellifera cecropia beschrieben wird.

Zwischen den Standorten Miesenbach und Klosterneuburg ließen sich bei Streckmaden bzw. Vorpuppen keine signifikanten Unterschiede bezüglich des Vorkommens von Varroa-Eiern (Kruskal-Wallis 1-Weg Rangvarianzanalyse, $\mathrm{n}=16, \mathrm{p}=0,692$, n.s.) oder des Vorkommens von Varroa-Larven (KruskalWallis 1-Weg Rangvarianzanalyse, $n=13, p=0,722$, n.s.) feststellen.

TAB. 9. - Häufigkeit des Vorkommens von Eiern und Larven der Varroamilbe in Zellen mit Streckmaden (SM) und Vorpuppen (VP)

TABL. 9. - Frequency of eggs and larvae of Varroa in cells with stretched larvae (SM) and prepupae (VP)

\begin{tabular}{|c|c|c|c|c|c|c|}
\hline $\begin{array}{l}\text { Volk } \\
\text { Colonie } \\
\text { number }\end{array}$ & $\begin{array}{c}\text { Anzahl } \\
\text { Zellen } \\
\begin{array}{c}\text { Number } \\
\text { cells }\end{array}\end{array}$ & $\begin{array}{c}\text { mit } \\
\text { Varroa } \\
\text { with } \\
\text { Varroa }\end{array}$ & $\begin{array}{l}\text { bef. } \mathrm{Z} \text {. } \\
\text { mit } \mathrm{Ei} \\
\text { with } \\
\text { eggs }\end{array}$ & $\begin{array}{c}\% \text { der } \\
\text { bef. Z. } \\
\% \text { of } \\
\text { inf. cells }\end{array}$ & $\begin{array}{l}\text { bef. Z. } \\
\text { mit Proton. } \\
\text { with } \\
\text { proton. }\end{array}$ & $\begin{array}{c}\% \text { der } \\
\text { bef. } Z \text {. } \\
\% \text { of } \\
\text { inf. cells }\end{array}$ \\
\hline 22 & 47 & 20 & 9 & 45,00 & 0 & 0,00 \\
\hline 120 & 116 & 72 & 38 & 52,78 & 1 & 1,39 \\
\hline 168 & 142 & 103 & 3 & 2,91 & 2 & 1,94 \\
\hline 436 & 30 & 23 & 11 & 47,83 & 0 & 0,00 \\
\hline 454 & 79 & 60 & 14 & 23,33 & 1 & 1,67 \\
\hline 459 & 14 & 14 & 7 & 50,00 & 1 & 7,14 \\
\hline 462 & 70 & 51 & 34 & 66,67 & 1 & 1,96 \\
\hline $465^{*}$ & 4 & 1 & 1 & 100,00 & 0 & 0,00 \\
\hline $483^{*}$ & 10 & 4 & 1 & 25,00 & 0 & $0,0(0)$ \\
\hline 494 & 84 & 59 & 12 & 20,34 & 2 & 3,39 \\
\hline 502 & 29 & 20 & 1 & 5,00 & 0 & 0,00 \\
\hline $514^{*}$ & 10 & 6 & 0 & 0,00 & 0 & 0,00 \\
\hline 522 & 91 & 51 & 3 & 5,88 & 0 & 0,00 \\
\hline 525 & 68 & 41 & 5 & 12,20 & 3 & 7,32 \\
\hline $528^{*}$ & 18 & 7 & 3 & 42,86 & 0 & 0,00 \\
\hline 531 & 51 & 21 & 1 & 4,76 & 0 & 0,00 \\
\hline $543^{*}$ & 3 & 3 & 0 & 0,00 & 0 & 0,00 \\
\hline $549^{*}$ & 13 & 7 & 0 & 0,00 & 0 & 0,00 \\
\hline $\mathrm{Pl}$ & 27 & 11 & 4 & 36,36 & 0 & $0,(00$ \\
\hline $\mathrm{n}=$ & 13 & 13 & 13 & 13 & 13 & 13 \\
\hline$\overline{\mathrm{x}}=$ & & & & 28,69 & & 1,9 \\
\hline $\mathrm{s}=$ & & & & 22,1 & & 2,6 \\
\hline
\end{tabular}

Legende : bef. $Z$. = befallene Zellen : Proton. = Protonymphe : ${ }^{*}=$ für die Mittelwertberechnung nicht berücksichtigte Völker (Anzahl Zellen mit Varroa $<10$ ). 
Zwischen dem Anteil der Streckmaden bzw. Vorpuppen mit Eiern und Larven der Varroamilbe in Prozent und dem Brut-Gesamtbefall ließ sich keine gesicherte Korrelation nachweisen (Rangkorrelation nach Spearman, $\mathbf{n}=15$, rs $=0,0572$, n.s.).

\section{DISKUSSION}

Die zu erwartende und in einigen Fällen bereits beobachtete Resistenzbildung der Varroamilbe gegen selektiv wirkende Akarizide (z.B. Phenothiazin, Amitraz) zwingt uns dazu, den natürlichen Regulations- und Anpassungsvorgängen zwischen Varroa und Bienenvolk in Zukunft verstärkte Aufmerksamkeit $\mathrm{zu}$ widmen. Aus den tropischen und subtropischen Klimaregionen gibt es bereits Befunde, die darauf hinweisen, daß sich unter noch näher zu untersuchenden Umständen zwischen europäischen beziehungsweise afrikanisierten Honigbienen und der Varroamilbe ein Gleichgewichtszustand einpendeln könnte, sodaß der Varroabefall unter der wirtschaftlichen Schadensschwelle bleibt (RutTner und Marx, 1984 ; Engels et al., 1986).

Unter jugoslawischen Verhältnissen (Sulimanovic et al., 1986) zeichnet sich möglicherweise ebenfalls der Beginn einer Anpassung zwischen Parasit und Wirt durch Erhöhung des Infertilitätsgrades der Varroaweibchen ab. Die Infertilitätsrate zeigte eine gewisse saisonale Abhängigkeit mit einem Maximum im Sommer und einem Minimum im Spätherbst.

Wertet man die vorliegenden Daten nach den Gesichtspunkten von SuLIMANOvic et al. (1986) aus, um sie vergleichen zu können, ergibt sich ein Infertilitätsgrad von durchschnittlich 28,9 Prozent $(\mathbf{n}=25$ Völker, $\mathbf{s}=12,1)$. Dieser Wert liegt jedoch um $26 \%$ unter dem von Sulimanovic angegebenen Mittelwert von $55,1 \%$ Infertilität und weist somit auf deutliche Unterschiede zwischen den untersuchten Völkern hin.

Der mittlere Befallsgrad war in unserem Fall mit $47 \%$ beinahe fünfmal so hoch, wie der mit $10,9 \%$ von Sulimanovic beobachtete. Kovac (1987) konnte an einem Bienenvolk in der Südsteiermark ebenfalls einen sehr hohen Infertilitätsgrad von durchschnittlich 58,4\% ermitteln.

Ohne Berücksichtigung eines Mehrfachbefalles von Brutzellen und der exakten Ermittlung der Altersstadien von Bienenbrut und Varroamilben stellen diese Arten der Ermittlung allerdings eine relativ ungenaue Schätzung des Infertilitätsgrades dar. In diesem Zusammenhang erscheint es uns wichtig, auf den gefundenen negativen Zusammenhang hinzuweisen, der zwischen Puppenalter der Biene und Befallsgrad der Brutzellen mit Varroamilben besteht. 
LAURENT und SANTAS (1987) konnten bei griechischen Bienenvölkern ebenfalls einen solchen Zusammenhang feststellen.

Dieser Rückgang im Befallsgrad im Laufe der Puppenentwicklung ist darauf zurückzuführen, daß in den stark befallenen Zellen die Puppen absterben und von den Bienen ausgeräumt werden. Größere Genauigkeit bringt die Ermittlung der Fortpflanzungsbilanz. Bei den von uns untersuchten Völkern ergab sich im Durchschnitt bei $25 \%(\mathrm{~s}=16,4)$ eine negative, bei $50,6 \%$ $(s=18,5)$ eine positive und bei $28,3 \%(s=12,8)$ der Zellen eine ausgeglichene Fortpflanzungsbilanz.

Bei den von uns untersuchten Bienenvölkern ist auch der große Anteil von Zellen mit Männchen auffällig. Im Durchschnitt waren in $57,6 \%$ der befallenen Zellen mit dem Puppenstadium PAD-SR ( $\mathrm{n}=28$ auswertbare Völker, $s=2,3$ ) Varroamännchen $z u$ finden. Waren Zellen von mehr als einer eingedrungenen Varroamilbe befallen, waren häufig auch 2 oder 3 Männchen pro Zelle zu finden. Laurent und Santas (1987) konnten hingegen in Südgriechenland nur bei $5 \%$ der befallenen Zellen Männchen feststellen. Wie diese 2 Ergebnisse zeigen, kann der Anteil von Zellen mit Varroamännchen sehr stark schwanken. Ob für diese Schwankungen klimatische, genetische oder andere, bisher unbekannte Faktoren - sowohl der Varroamilbe, als auch der Bienenvölker - hauptverantwortlich sind, läßt sich derzeit noch nicht entscheiden.

Nach unseren Ergebnissen bestehen zwischen Apis mellifera cecropia (Ifantidis, 1983) und Apis mellifera carnica offensichtlich beträchtliche Unterschiede in der Zeitspanne zwischen dem Eindringen fortpflanzungswilliger Varroaweibchen in Zellen vor der Verdeckelung und dem Beginn der Eiablage von Varroa.

Laurent und Santas (1987) konnten im Stadium der «Pränymphe " (= Zeit nach der Verdeckelung bis zur Puppenhäutung) keine Nachkommen von Varroa feststellen und schlossen daraus, daß die Varroamilbe in dieser Zeit noch keine Eier ablegen kann. Eine Eiablage konnten sie erst in der Umwandlungsphase der Pränymphe in die Puppe beobachten. Merkwürdigerweise finden diese beiden Autoren in der anschließenden Phase der Puppe mit weißen Augen bereits Eier, Proto- und Deutonymphen sowie adulte Milbenmännchen. Dieses Ergebnis steht damit in krassem Widerspruch zu der von IFANTIDIS (1983) gemachten Beobachtung, daß die Eiablagen in einem Rhythmus von 30 Stunden erfolgen.

Berücksichtigt man die von LAURENT und SANTAS (1987) angegebene Entwicklungszeit für die Milbenmännchen von 3 bis 4 Tagen, ist es noch merkwürdiger, daß bei einer Gesamtentwicklungsdauer des Stadiums «Puppe Augen weiß" von 3 Tagen die ersten Milbeneier nicht mindestens 2 bis 3 Tage vor der Verpuppung zu finden waren. Es wäre sehr wünschenswert, den 
Verdeckelungszeitpunkt bei Apis mellifera cecropia unter den klimatischen Verhältnissen Griechenlands exakt zu bestimmen. Unter Umständen werden die Zellen von Apis mellifera cecropia in Griechenland bereits früher verdekkelt, als von Apis mellifera carnica in Mitteleuropa.

Bei den von uns untersuchten Völkern waren nur in 5 Zellen mit dem Puppenstadium PAR bereits Männchen zu finden. Ab dem Stadium PADwaren Männchen regelmäßig anzutreffen.

Damit könnte sich theoretisch auch in unseren Breiten ein Milbenmännchen in 3 Tagen entwickeln. Viel wahrscheinlicher ist allerdings, da 3 auch in den Fällen sehr früh auftretender Männchen die Entwicklunszeit etwa 5 Tage beträgt, aber die Eiablage der Varroamilben zu einem früheren Zeitpunkt erfolgt. Diese Vermutung wird auch durch das Auftreten des Milbenstadiums II-im (nach der Nomenklatur von Ifantidis, 1983) im Puppenstadium PADgestützt. Als Ursache für die extrem rasche Milbenentwicklung — auch die Zeitspanne vom Ei bis zum Deutonymphenstadium der Weibchen ist gegenüber dem nördlichen Griechenland (IFanTIDIS, 1983) um einen Tag verkürzt nennen LaURENT und SaNTaS (1987) die hohen Temperaturen, die dazu führen, daß in den Bienenstöcken kein Temperaturausgleich mehr aufrechterhalten werden kann.

Wie das in Abb. 6 dargestellte Schema zeigt, konnten wir im Unterschied zu IFANTIDIS (1983) bei $25 \%$ aller Zellen mit Streckmaden bzw. Vorpuppen bereits Eier der Varroamilbe und bei $1,6 \%$ der Zellen Eier und Larven in derselben Zelle finden. (Berücksichtigt wurden nur Völker, bei denen mehr als 10) varroabefallene Zellen des Stadiums SM/VP ausgewertet werden konnten.) Das bedeutet. daß das erste Ei bereits unmittelbar nach oder sogar schon vor der Verdeckelung (was in einem Fall zu beobachten war!) abgelegt wurde. Auf jeden Fall erfolgte die erste Eiablage bei einem Teil der von uns untersuchten Völker früher, als von IfaNTIDIS (1983) beobachtet, der den Zeitpunkt der ersten Eiablage mit 60 Stunden nach der Verdeckelung festsetzt. (Der Bezug der Eiablage auf den Verdeckelungszeitpunkt erscheint uns in gewisser Weise problematisch, wenn man die in der Literatur dafür angegebenen Werte samt ihren Schwankungen kennt (z.B. Verdeckelung nach WeIss (1986) 9,5 Tage nach der Eiablage, nach Rembold et al. (1980) 7-8,5 Tage nach der Eiablage. Hinzu kommt, daß sich die im Labor unter konstanten Bedingungen ermittelten Werte nicht immer mit den unter natürlichen Bedingungen beobachteten, decken müssen.)

Auch nach den Ergebnissen von Schulz (1984) beginnt Varroa spätestens am 10.-11. Entwicklungstag der Biene mit der Eiablage, während das Eindringen in die Zelle etwa am 7. Entwicklungstag erfolgt.

Rein rechnerisch müßte sich dadurch in den Zellen mit vorzeitiger Eiab- 
lage die Zahl der Nachkommen pro Varroa um mindestens ein fertiles Weibchen erhöhen. Tatsächlich lag die gefundene durchschnittliche Nachkommensrate pro Varroa bei $1,36(\mathrm{~s}=0,38, \mathrm{n}=28$ Völker) ausgereiften weiblichen Nachkommen.

Dieser Wert liegt fast um das Doppelte über dem von IFANTIDIS (1984) gefundenen Durchschnittswert von nur 0,71 ausgereiften Varroamilben pro eingedrungenem Weibchen in der Arbeiterinnenbrut, deckt sich aber recht gut mit dem von Schulz (1983) bei Arbeiterinnenbrut festgestellten Wert von 1,4 adulten weiblichen Nachkommen pro fertilem Varroaweibchen.

Bei den von uns untersuchten Völkern zeigte sich eine starke Abnahme der Nachkommensrate pro Varroa mit steigender Anzahl von Müttern pro Zelle. Ab 4 Müttern pro Zelle sank die Nachkommensrate pro Varroa unter 1. Da aber selbst bei einem Befall von $50 \%$ der Brutzellen erst 9,1\% aller befallenen Zellen 4 oder mehr als 4 Mütter pro Zelle aufweisen, dürfte dieser Begrenzungsfaktor erst bei starkem Befall eine größere Rolle spielen, der für die meisten Völker jedoch bereits einen Letalfaktor darstellt.

Nach den Werten von Ifantidis (1983) für die Entwicklungsdauer der einzelnen Varroastadien dürften im Puppenstadium PAD- noch keine Milben des Stadiums II-im (nach der Nomenklatur von IFANTIDIS, 1983) auftreten.

Tatsächlich konnten wir aber in 7 , nach diesem Kriterium auswertbaren Völkern, bei durchschnittlich $26,1 \%(\mathrm{~s}=13,2)$ aller befallenen Zellen mit dem Puppenstadium PAD- bereits das Varroastadium II-im antreffen. Berücksichtigt für die Mittelwertberechnung wurden nur jene 7 Völker der Standorte Miesenbach und Klosterneuburg, bei denen in den untersuchten Wabenproben mehr als 10 Zellen mit PAD- gefunden wurden. (Insgesamt waren dies 183 Zellen).

Der ermittelte Wert von 26,1\% deckt sich gut mit den gefundenen $28,7 \%$ der varroabefallenen Streckmaden/Vorpuppen mit Varroaeiern.

Setzt man den Prozentsatz an Streckmaden/Vorpuppen mit Eiern oder Larven der Varroa in Beziehung zur durchschnittlichen Anzahl von Nachkommen pro Varroa, so nimmt bei steigendem Prozentsatz auch die durchschnittliche Nachkommensanzahl pro Varroa zu. Aufgrund des zu geringen Datenmaterials $(n=13)$ ließ sich diese Beziehung statistisch jedoch nicht absichern. Greift man sich zum Beispiel aus Tab. 5 jene 7 Fälle mit mehr als 1,5 Nachkommen pro Varroa heraus und vergleicht sie mit der Häufigkeit des Auftretens von Eiern bzw. Larven auf Streckmaden/Vorpuppen, so ergibt sich bei den 3 auswertbaren Fällen (auf 4 Brutwabenstücken fanden sich keine Streckmaden oder Vorpuppen) mit durchschnittlich 53,2\% ein deutlich höherer Wert, als bei den übrigen auswertbaren Völkern $(\mathrm{n}=18)$, mit durchschnittlich 30,1 Prozent. 
Der gefundene Unterschied von $23 \%$ zeigt, daß es offenbar auch innerhalb der Varroapopulation eines Bienenstandes beträchtliche Unterschiede gibt, was den Zeitpunkt der ersten Eiablage nach dem Eindringen in die Brutzellen anlangt.

Fuchs (1985) und eigene Untersuchungsergebnisse zeigten, daß die Anteile der Milbenpopulation, die in die Bienenbrut eindringen, auch bei gleichen Brutmengen von Volk zu Volk außerordentlich unterschiedlich sein können.

Möglicherweise handelt es sich bei diesen $30 \%$ der Milben, die offenbar frühzeitig Eier ablegen, um solche, die gleich nach dem Schlüpfen der Jungbiene zum zweitenmal eine Brutzelle zur Eiablage aufsuchen. Dies würde sich sowohl mit der Aussage von Schulz (1984) decken, daß Varroaweibchen beim zweiten Befall einer Brutzelle rascher in die Zellen einzudringen scheinen, als beim ersten Befall, als auch mit der Aussage von Grobov (1977), daß Milben, die zur erneuten Eiablage in Zellen eindrangen, dies nahezu unmittelbar nach dem Schlüpfen der Jungbienen taten. Nach Kamburov et al. (1975) und Mikitıuk et al. (1976) sollen $78 \%$ aller Milben einmal, $18 \%$ zweimal und $4 \%$ dreimal in Eilage gehen.

Wenn man die Untersuchungen von HÄNEL (1984 und 1987) berücksichtigt, die eine zweistufige, hormonale Steuerung der Eiablage der Varroamilbe durch das Juvenilhormon der Biene wahrscheinlich erscheinen lassen, wäre es denkbar, daß diese Milben in die Zellen eindringen und Eier ablegen können, ohne erneut an Bienen saugen zu müssen.

Für die Praxis ist es in Zukunft wichtig, einfach zu ermittelnde Selektionskriterien zu finden, die dem Imker das frühzeitige Erkennen und Ausscheiden von varroaanfälligen Völkern ermöglichen können. Völker mit hohem Infertilitätsgrad bei gleichzeitig niedrigem Befallsgrad oder spätem Eiablagebeginn der Varroaweibchen sollten bevorzugt zur Nachzucht verwendet werden.

Völker, die bereits bei niedrigem Varroabefall Brutschäden oder eine gestörte Entwicklung zeigen, sollten möglichst frühzeitig ausgeschieden und auch nicht für die Brutablegerbildung herangezogen werden.

Eingegangen im November 1987. Angenommen im April 1988.

\section{DANKSAGUNG}

Dem Bundesministerium für Land- und Forstwirtschaft danken wir für die Genehmigung, die statistischen Auswertungen am Land- und Forstwirtschaftlichen Rechenzentrum durchführen zu dürfen . Für die Betreuung bei der Datenanalyse sei Herrn Dipl. Ing. Leitl herzlich gedankt. 


\section{RÉSUMÉ \\ RECHERCHES SUR LA CORRÉLATION ENTRE LE TAUX DE REPRODUCTION DE VARROA JACOBSONI OUD. ET LE TAUX D'INFESTATION DES COLONIES D'ABEILLES}

\section{Introduction}

Les colonies d'abeilles d'un même rucher présentent souvent de grandes différences dans le taux d'infestation par Varroa et dans la dynamique des populations de l'acarien. Parce que les causes de ces différences soulc̀vent de nombreuses questions, il était nécessaire d'analyser les interrelations entre le taux d'infestation et le taux de reproduction de Varroa.

\section{Méthodes}

On a étudié 33 colonies d'Apis mellifica L. carnica situées en 2 endroits climatiquement différents. En septembre 1986 on a prélevé dans chaque colonic des échantillons de couvain et d'abeilles et estimé leur taux d'infestation, le degré d'infertilité de Varroa et son taux de reproduction. L'estimation de l'âge des nymphes a été faite d'après les données de JAY (1962). Le bilan de reproduction a été établi à l'aide d'un planning (Tabl. 1) basé sur les temps de développement de Varroa (Ifantidis, 1983) et de l'abeille (WEISs, 1986).

\section{Résultats}

Le taux moyen d'infestation des abeilles est de $27 \%$, mais varie beaucoup d'une colonie à l'autre (Tabl. 2). II n'y a pas de différence significative entre les 2 licux. Le taux moyen d'infestation du couvain est de $50 \%(\mathrm{n}=33, \mathrm{~s}=16,6)$. Il décroît lorsque l'âge des nymphes augmente ; ceci est dû à la mortalité et à l'élimination des larves d'abeilles dans les cellules fortement parasitées (Tabl. 8). Il n'y a aucune relation statistiquement significative entre lo taux d'infestation du couvain et celui des abeilles adultes. Le pourcentage de cellules infestées dans lesquelles Varroa ne s'est pas reproduit (c'est-à-dire, sans ponte) est en moyenne de $7 \%$, mais varie grandement d'une colonie à l'autre (Tabl. 7). Dans 2,9\% des cellules infestécs (PAD-SR) on n'a trouvé que des descendants mâles (Tabl. 7).

Le nombre de descendants par Varroa (Tabl. 5) varie grandement d'une colonic à l'autre (minimum 0,19 , maximum 2,14). Il n’y a néanmoins pas de corrélation statistiquement significative entre le nombre de descendants et le pourcentage de survie durant l'hiver. Les colonies survivantes ont plus de descendants (1,5 par Varroa) que les colonies mortes (1,3 par Varroa). Ces résultats concordent avec la diminution significative du taux de reproduction lorsqu'augmentent les taux d'infestation des abeilles et du couvain (Fig. 1 et 2 ).

Le pourcentage de cellules ayant un bilan reproducteur de Varroa négatif augmente significativement avec le taux de parasitisme (Fig. 3). Par contre le pourcentage de cellules ayant un taux de multiplication de Varroa positif décroît très significativement. Lc pourcentage de cellules ayant un bilan nul décroît légèrement, mais non significativement, lorsqu'augmente le taux de parasitisme.

Un taux d'infestation du couvain en augmentation provoque un accroissement hautement significatif des acariens par cellule (Fig. 4). Le nombre de descendants par Varroa décroît de façon hautement significative lorsque le nombre d'acariens par cellule augmente (Fig. 5).

$30 \%$ environ des cellules avec prénymphe présentent déjà des ceufs ou des larves de Varroa (Tabl. 9). Cela signifie que chez Apis mellifica carnica une plus grande proportion d'acariens doivent commencer à pondre plus tôt qu'on ne le suppose généralement. Les $30 \%$ des femelles de Varroa qui pondent précocement sont probablement des acariens qui entament un second cycle reproducteur sans s'alimenter plus longtemps sur l'abcille adultc.

\section{Conclusion}

Pour élever des reines, les apiculteurs devraient préférer des colonies dans lesquelles Varroa a un taux élevé d'infertilité ou une ponte tardive. Des colonies qui présentent déjà des maladies du couvain ou des troubles du développement tout en ayant un niveau de Varroa faible devraient être éliminées dès que possible et ne pas être utilisées pour former des nuclei. 


\section{SUMMARY \\ INVESTIGATIONS ON THE CORRELATION BETWEEN RATE OF REPRODUCTION OF VARROA JACOBSONI AND INFESTATION RATE OF HONEYBEE COLONIES}

\section{Introduction}

Honey bee colonies within one apiary often show great differences in infestation rate and Varroa population dynamics. Because there are many questions about the reasons for these differences, the interdependence of infestation rate and Varroa offspring should be analysed.

\section{Methods}

33 colonies of Apis mellifera L. carnica in two different climatic locations were investigated. In September 1986 brood and bee samples of each colony were collected and Varroa offspring, infestation rates of bees and brood cclls, infertility and Varroa multiplication balance were estimated. According to JaY (1962), Ifantidis (1983) and WeIss (1986) a schedule was cstablished (Table 1) to cstimate pupal age and Varroa multiplication balance.

\section{Results}

Mean bee infestation rate of all colonics was $27 \%$, but varied widely between colonies (Table 2). There were no significant differences between the two locations. Mean brood infestation rate was $50 \%$. With increasing pupal age, brood infestation rate decreased due to dying and removed bee larvae in multiple parasitized cells (Table 8). Brood and bee infestation rates do not show any significant statistical connection. The mean percentage of cells without Varroa propagation was $7 \%$ and varicd widely between colonies (Table 7). In $2.9 \%$ of infested cells (PAD-SR) only male offspring were found (Table 7).

Offspring numbers per Varroa (Table 5) varied greatly between colonies (minimum 0.19, maximum 2.14). Nevertheless, there was no significant statistical correlation between offspring numbers and percentage of survival during winter. Surviving colonics had higher offspring numbers $(1.5$ per Varroa $)$ than dead colonies (1.3 per Varroa). These findings are in accordance with the significant decrease in offspring rate with increasing bec- and brood infestation rate (Fig. 1).

The percentage of cells with negative Varroa multiplication balance increased significantly with increasing parasitization rate (Fig. 3). On the contrary percentage of cells with positive Varroa multiplication rate decreases were highly significant. Percentage of cells with equalized Varroa balance showed a slight, but not significant declinc.

Increasing brood infestation rate caused a highly significant increasc in mites per cell (Fig. 4). Offspring number per Varroa decreased highly significantly with increasing numbers of mites per cell (Fig. 5).

About $30 \%$ of cells with stretched larvae or prepupac already showed some eggs or larvae of Varroa (Table 9). That means that in Apis mellifera carnica, a greater proportion of mites must begin oviposition earlier than generally supposed. The $30 \%$ of Varroa females that oviposite early, are probably mites which begin a second reproduction cycle without sucking on bees for a longer time.

\section{Conclusions}

For breeding queens, beekeepers should prefer colonies with a high level of infertility or delayed oviposition by Varroa mites. Colonies which already show brood diseases or development disturbances at low levels of Varroa infestation should be eliminated as early as possible and not be used for nuclei formation. 


\section{LITERATUR}

Bretschko J., 1987. - Widersprechende Bekämpfungserfolge und deren Ursachen. Bienenwelt, 29, 245246.

Engels W., Goncalves L.S., Steiner J., Buriolla A.H., Cavichio Issa M.R., 1986. - Varroa-Befall von Carnica-Völkern in Tropenklima. Apidologie, 17, 203-216.

Fuchs S., 1985. - Untersuchungen zur quantitativen Abschätzung des Befalls von Bienenvölkern mit Varroa jacobsoni Oud. und zur Verteilung des Parasiten im Bienenvolk. Apidologie, 16, 343-368.

Grobov O., 1977. - Varroasis, a honeybee disease. Bukarest, Apimondia Publ. Housc, 46-70.

Hänel H., 1984. - Einfluß des Bienenalters auf die Vermehrung von Varroa jacobsoni. Apidologie, 15, 255.

Hänel. H., 1987. - Mögliche Regulierung der Vermehrung der Bienenmilbe Varroa jacobsoni durch ein Wirtshormon : Juvenilhormon III. Alpenländische Bienenzeitung, 75, 117-125.

Herold J., 1986. - Die Varroamilbe und der Imker. Imkerfreund, 41, 122.

Ifantidis M.D., 1983. - Ontogenesis of the mite Varroa jacobsoni in worker and drone honeybee brood. J. Apic. Res., 22, 200-206.

IfANTIDIS M.D., 1984. - Parameters of the population dynamics of the Varroa mite on honeybees. $J$. Apic. Res., 23, 227-233.

Imdorf A., Fluri P., Gerig L., 1987. - Imkern mit varroaverseuchten Bienenvölkern. 2. Teil : Integrierte Betriebsweise. Schweizerische Bienenzeitung, 110, 433-438.

JAY S.C., 1962. - Colour changes in honeybee pupae. Bee World, 43, 119-122.

JAY S.C., 1963. - The development of honeybees in their cells. J. Apic. Res., 2, 117-134.

Kamburov G. et al., 1975. - Zit. nach Grobov O. (1977), a.a.O.

Kovac H., 1987. - Die Befallsentwicklung der Milbe Varroa jacobsoni Oud. in Bienenvölkern und Auswirkungen der Parasitierung auf die Einzelbiene (Apis mellifica carnica Pollm.). Dissertation an der Universität Graz.

Laurent J.C. u. Santas L., 1987. - Etude du développement larvaire de Varroa jacobsoni Oud. Apidologie, 18, 53-60.

LiEBIG G., 1986. - Varroa-Leitfaden. Stuttgart, Landesverband Würtembergischer Imker.

Mikitúк V.V. et al., 1976. - Zit. nach Grobov O. (1977), a.a.O.

Rembold H., Kremer J.P., Ulrich G.M., 1980. - Characterization of postembryonic developmental stages of the female castes of the honey bee, Apis mellifera L. Apidologie, 11, 29-38.

Ruttner F., Marx G., 1984. - Beobachtungen über eine mögliche Anpassung von Varroa jacobsoni an Apis mellifera L. in Uruguay. Apidologie, 15, 43-62.

Schulz A., 1983, - Fortpflanzungsdynamik bei Varroa jacobsoni. Apidologie, 14, 269-270.

Schulz A., 1984. - Reproduktion und Populationsentwicklung der parasitischen Milbe Varroa jacobsoni Oud. in Abhängigkeit vom Brutzyklus ihres Wirtes Apis mellifera L. Apidologie, 15, 401-420.

Sulimanovic D., Rutener F., Tomac T., Pechhacker H., 1986. - Reduced Varroa reproduction in colonies of a strain in Dalmatia. Symp. "Health protection of honeybees " in Zagreb (YU) ; 29.92.101986.

Weiss K., 1986. - Beobachtungen zum Entwicklungsverlauf der drei Bienenwesen. Imkerfreund, 41, 188-190. 